\title{
Pseudonodule Formation by Wild-Type and Symbiotic Mutant Medicago truncatula in Response to Auxin Transport Inhibitors
}

\author{
Adriana P. Rightmyer and Sharon R. Long \\ Department of Biology, Stanford University, Stanford, CA 94305-5020, U.S.A.
}

Submitted 29 April 2011. Accepted 21 July 2011.

\begin{abstract}
Rhizobium and allied bacteria form symbiotic nitrogen-fixing nodules on legume roots. Plant hormones play key roles in nodule formation. We treated Medicago truncatula roots with auxin transport inhibitors (ATI) N-(1-naphthyl)phthalamic acid (NPA) and 2,3,5-triiodobenzoic acid (TIBA) to induce the formation of pseudonodules. M. truncatula mutants defective for rhizobial Nod factor signal transduction still formed pseudonodules in response to ATI. However, a M. truncatula ethylene-insensitive supernodulator, sickle 11, did not form pseudonodules in response to TIBA, suggesting that the ethylene response pathway is involved in ATI-induced pseudonodule formation. We compared the transcriptional responses of $M$. truncatula roots treated with ATI to roots inoculated with Sinorhizobium meliloti. Some genes showed consistently parallel expression in ATIinduced and Rhizobium-induced nodules. For other genes, the transcriptional response of $M$. truncatula roots 1 and 7 days after ATI treatment was in the opposite direction to roots treated with $S$. meliloti; then, by 21 days, the transcriptional patterns for the two conditions became similar. We silenced 17 genes that were upregulated in both ATI and $S$. meliloti treatments to determine their effect on nodule formation. Some gene-silenced roots showed a decrease in nodulation efficiency, suggesting a role in nodule formation but not in later nodule functions.
\end{abstract}

Formation of symbiotic root nodules in response to rhizobia involves signal exchange between legume plants and bacteria, triggering a cascade of developmental events. These steps require action of both bacterial and plant genes. In wild-type (WT) nodules, bacteria stimulate plants to form nodules by means of the Nod factor (NF) signal, and invade via infection threads into dividing root nodule cells. A bacterial mutant such as Sinorhizobium meliloti exoA, which lacks succinoglycan extracellular polysaccharide, provokes nodule formation on alfalfa (Medicago sativa) but cannot invade. Thus, exoA $A^{-}$bacteria yield uninfected ("empty") nodules devoid of bacteroids, the differentiated nitrogen fixing symbiotic form of rhizobia (Leigh et al. 1985). Such empty nodules have relatively normal morphology and express genes for early nodulins (ENOD) characteristic of true nodules in early stages of development.

Corresponding author: S. R. Long; Telephone: +1650723 3153; Fax: +1 650725 8309; E-mail: srl@ stanford.edu

* The $e$-Xtra logo stands for "electronic extra" and indicates that three supplementary tables, two supplementary figures, and supplementary Materials and Methods information is published online.
Thus, bacteria that can produce NF are capable of eliciting basic nodule morphogenesis whether or not invasion occurs.

Some chemical treatments or gene mutations can lead to formation of pseudonodules, which are nodule-like root structures that emerge in the absence of NF. Structurally, pseudonodules are comparable to the empty nodules stimulated by noninvasive bacteria such as the $e x o A^{-} S$. meliloti (Hirsch et al. 1989) .

Two lines of evidence imply a role for cytokinin in pseudonodule formation. The application of Escherichia coli bearing a plasmid that produces cytokinin (pTZS) (Long and Cooper 1988) causes $M$. sativa roots to produce pseudonodules. Cytokinin-induced $M$. sativa pseudonodules are morphologically similar to an empty Sinorhizobium sp.-induced nodule, and they express some ENOD (Cooper and Long 1994; Long and Cooper 1988). Further evidence for the role of cytokinins emerged from discovery that a Lotus japonicus gain-of-function mutation in the cytokinin receptor LHK1 causes the root to form spontaneous nodules in the absence of rhizobial bacteria (Tirichine et al. 2007). These experiments imply that cytokinin directly or indirectly plays a role in the formation of root nodules.

Pseudonodule formation also is elicited on $M$. sativa roots by application of auxin transport inhibitors (ATI) such as naphthylphthlamic acid (NPA) and 2,3,5-triiodobenzoic acid (TIBA) (Hirsch et al. 1989). These pseudonodules resemble empty nodules elicited by $S$. meliloti exopolysaccharide (exo) mutants at the histological and molecular level (Hirsch et al. 1989). Related evidence shows that rhizobial inoculation of $M$. truncatula roots causes a decrease in auxin transport, an effect also caused by NPA (Wasson et al. 2006). Whether the mechanisms of ATI-induced and cytokinin-induced nodules are related has been a source of speculation (Van De Wiel et al. 1990).

Ethylene appears to play an important role in nodule regulation. Oldroyd and associates (2001) reported that ethylene inhibits early plant responses to NF, including initiation of calcium spiking, which, in turn, regulates downstream responses such as transcription. Sickle has a mutation in the $M$. truncatula homolog of EIN2, a positive regulator of ethylene signaling in Arabidopsis (Alonso et al. 1999; Penmetsa et al. 2008). Sickle is both ethylene insensitive and acts as a "supernodulator," forming abnormally high numbers of nodules (Penmetsa and Cook 1997; Penmetsa et al. 2008). Heidstra and associates (1997) observed distinct tissue specificity of gene expression for ACC oxidase, required for ethylene synthesis. Results from this and other experiments implied that ethylene was a component in guiding cell division patterns in nodule morphogenesis. It is possible that ethylene plays more than one role in regulating nodule formation.

The role of hormones in nodulation is complex and not limited to auxin, cytokinin, and ethylene. Pea mutants with defi- 
cits in gibberellins or brassinosteroids display reduced nodule organogenesis (Ferguson et al. 2005). Exogenous jasmonic, salicylic, and abscissic acid application all diminish early NF responses (Stacey et al. 2006; Sun et al. 2006; Suzuki et al. 2004). Although it is clear that plant hormones have a role in nodule development, elucidating the mechanism by which they regulate nodule development is a complex task.

To identify genes involved in hormone-dependent nodule organogenesis, we used microarrays to compare the transcriptional profile of $M$. truncatula WT root nodules with that of pseudonodules formed in response to NPA and TIBA. We found that the transcriptional profiles differ at early time points but mature pseudonodules and bacterial nodules eventually display a similar transcriptional profile. To determine whether pseudonodule formation involves genes known to be required for nodule development, we tested WT and symbiosis-deficient $M$. truncatula for their ability to form pseudonodules in response to ATI. Early pseudonodule responses are not dependent on the known NF-signaling pathway. However, ATI-induced pseudonodule formation requires a functional copy of the ethylene response gene, EIN2.

\section{RESULTS}

\section{M. truncatula forms pseudonodules in response to ATI.}

We assayed pseudonodule formation on M. truncatula in response to different concentrations of the auxin transport inhibitors NPA and TIBA. Pseudonodules were distinguished from nodules formed by WT $S$. meliloti by histological characteristics such as their more diffuse meristem and vascular tissue differentiation at the proximal part of the pseudonodule (Fig. 1). Pseudonodules were visible as early as 14 days after ATI treatment (daa) in $M$. truncatula (data not shown) and had formed by 21 daa at all tested concentrations of NPA and TIBA (Fig. 2). Although pseudonodule numbers varied from plant to plant within an applied concentration of ATI, we generally observed more pseudonodules per plant using TIBA than NPA (Fig. 2). For all further experiments, each ATI was applied at a standard concentration of $100 \mu \mathrm{M}$.
M. sativa also forms pseudonodules in response to bacteria engineered to produce the cytokinin precursor trans-zeatin (Long and Cooper 1988); however, this technique failed to induce pseudonodules on M. truncatula (A. Parra and L. Smith, unpublished results).

Because NF-signaling and nodule number are diminished by ethylene (Oldroyd et al. 2001); we asked whether pseudonodule formation was likewise affected. By varying levels of available ethylene, we found that TIBA-elicited pseudonodule formation was not decreased by any tested level of ethylene, whereas NPA effects were inhibited slightly (Supplementary Fig. S1). To redress this mild ethylene effect in all further experiments, plants were grown in a standard medium containing $1 \mu \mathrm{M} \alpha$-aminoisobutyric acid (AIB), which blocks ethylene production by inhibiting ACC synthase. A complex role of ethylene is suggested by genetic analysis (below).

\section{Pseudonodule formation is independent of the NF-signaling pathway.}

To determine whether ATI-elicited pseudonodule formation acts through known pathways for nodule development, we evaluated this behavior in $M$. truncatula $\mathrm{Nod}^{-}$mutants with altered NF perception and signaling. All $\mathrm{Nod}^{-}$mutants from $n f p^{-}$to $n i n^{-}$formed pseudonodules in response to either NPA or TIBA (Fig. 3A), indicating that the basic machinery for cell division and morphogenesis triggered by ATI is independent of the NF-signaling pathway. We observed that the mutants varied in their ability to form pseudonodules: WT plants formed an average of 8 pseudonodules while $n f p$ and ritl formed an average of 1 and 12.5 pseudonodules, respectively.

We also evaluated the ATI response of three $M$. truncatula "supernodulation" mutants (skll-1, lss, and sunn) to determine whether they made higher-than-WT numbers of pseudonodules. Two supernodulators, lss and sunn, formed pseudonodules in response to both ATI within the range seen on A17 (Fig. 3B). Therefore, these supernodulators are not super-pseudonodulators. However, given the variability in the pseudonodule number per plant (Fig. 3B) within lss and sunn, we cannot rule out an effect of these genes on control of pseudonodule formation.
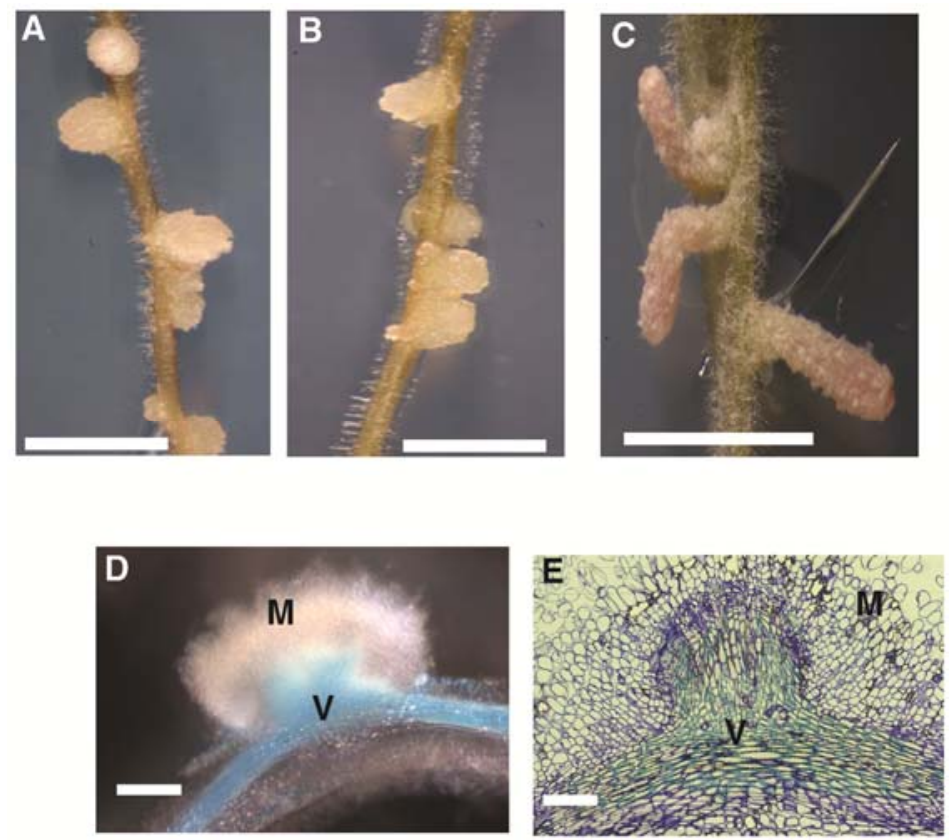

Fig. 1. Pseudonodules formed in Medicago truncatula roots at 21 days after auxin transport inhibitor treatment (daa) in response to A, $200 \mu \mathrm{M}$ N-(1naphthyl)phthalamic acid (NPA) and B, $200 \mu \mathrm{M}$ 2,3,5-triiodobenzoic acid (TIBA). C, Nodules formed by Sinorhizobium meliloti Rm1021 in M. truncatula roots. A to C: scale bar $=1 \mathrm{~mm}$. D, Enlarged pseudonodule with a diffuse meristem $(\mathrm{M})$ and a bifurcated vascular bundle $(\mathrm{V})$; scale bar $=250 \mu \mathrm{m}$. $\mathbf{E}$, Longitudinal section of a TIBA-induced pseudonodule formed 30 daa; scale bar $=55 \mu \mathrm{m}$. 
In contrast, we saw a distinctly different result with skl1-1, which carries a mutation in the ethylene-signaling component EIN2. Only $8 \%$ of skl1-1 mutants formed pseudonodules with NPA by 21 daa (Fig. 3B), and none formed pseudonodules in response to TIBA, even when assayed as late as 40 daa.

We assessed other expected ethylene-related phenotypes in our mutant. In WT $M$. truncatula plants, ethylene causes reduction of root growth; in skl1-1 plants, ethylene has no effect, as would be expected for an EIN2 mutant. TIBA likewise causes decreased root growth on WT M. truncatula (data not shown). We observed that root length in skl1-1 was not affected by TIBA (Supplementary Fig. S2). Failure of M. truncatula skl1-1 to form pseudonodules in response to TIBA implies a connection between TIBA action and the ethylene response pathway.

\section{Distinct root transcriptional profiles}

at 1 to 7 days following ATI versus bacterial treatment.

We surmised that genes expressed in both $S$. meliloti-induced nodules and ATI-induced pseudonodules represent functions involved in basic morphogenesis. We first compared transcription profiles for early stages of both processes in order to identify genes that may be involved in the initial stages of nodule organogenesis.

We examined gene expression in M. truncatula roots inoculated with $S$. meliloti 1021 at five time points: 1, 4, 7, 14, and 21 days after inoculation with live bacteria (dai) (Starker et al. 2006). From this dataset, we selected tentative consensus sequences (TC) that were differentially regulated in roots inoculated with S. meliloti 1021 compared with control buffertreated roots. To qualify for inclusion in our dataset, a sequence had to appear in one or more time points in the set of differentially expressed transcripts, no matter whether the direction of differential change was increased or decreased RNA abundance. We term this collective dataset the nodulation differential sequence set (NOD-DSS), because it defines a set of genes that are differentially expressed at one or more time point during nodule formation elicited by WT bacteria.

We established transcription profiles for ATI-treated roots and identified a set of sequences that are differentially expressed in roots treated with NPA or TIBA at 1 and 7 daa compared with control buffer-treated roots (discussed below). This dataset, ATIDSS, defines a set of genes that are differentially expressed during pseudonodule formation. The expression of these genes at 21 daa was added to Figure 4 for comparison purposes (discussed below). The NOD-DSS and ATI-DSS sets were assembled independently, and include all sequences with either increased or decreased expression relative to buffer controls. To explore the overlap and exclusion of the two sets, we began by noting sequences that were present in both DSS sets (Fig. 4). This comparison explicitly aimed to examine ATI-caused transcription change with respect to the timing of normal nodulation.

We identified 64 TC present in both ATI-DSS and NODDSS (Fig. 4). Among these, 28 TC were present in both NPA and TIBA treatments, 24 TC showed transcriptional changes only in response to NPA, and 12 TC showed changes only in response to TIBA (Fig. 4). The 64 sequences found in both the ATI-DSS and NOD-DSS fall into three main expression patterns, or "clusters" (Fig. 4, top panel and numbers to the left of array heat map).

NPA $\square$ TIBA

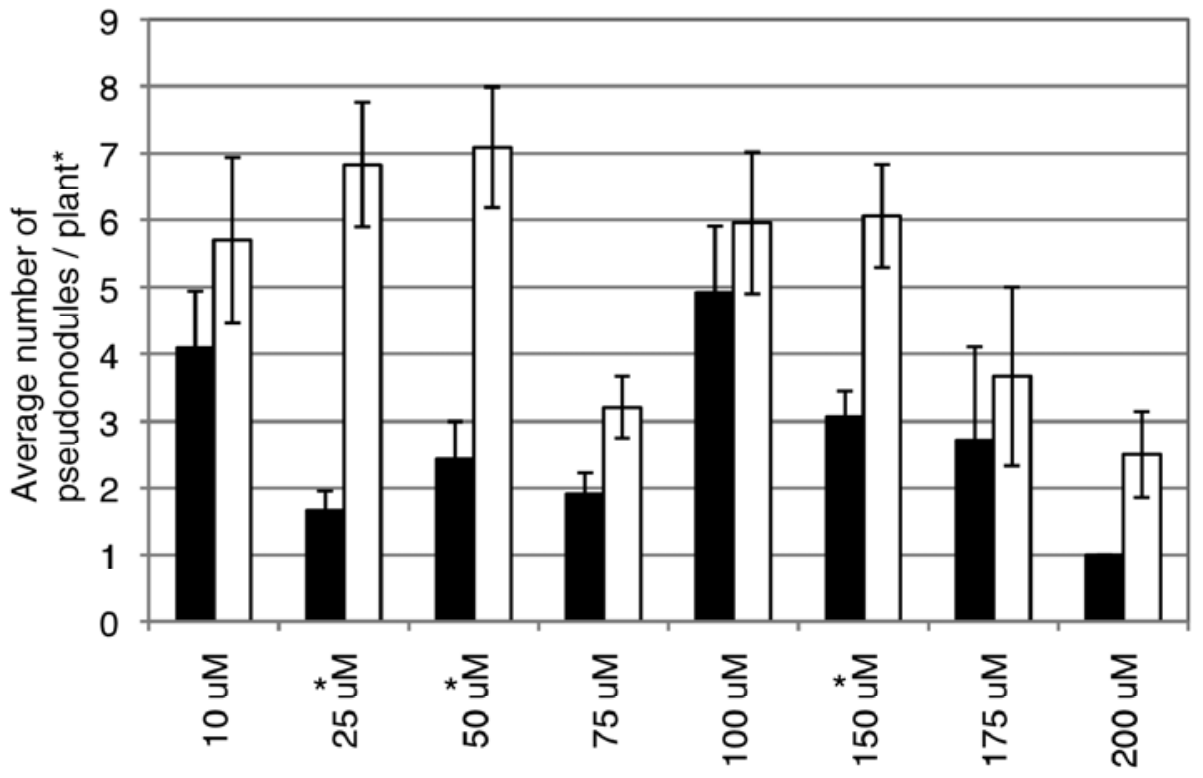

\begin{tabular}{|c|c|c|c|c|c|c|c|c|c|}
\hline \multirow{2}{*}{$\begin{array}{l}\text { Plants with } \\
\text { pseudonodules } \\
\text { (\%) }\end{array}$} & $\frac{\varangle}{2}$ & 28 & 23 & 18 & 28 & 58 & 38 & 18 & 3 \\
\hline & $\underline{\underline{a}}$ & 25 & 43 & 52 & 40 & 38 & 43 & 8 & 10 \\
\hline
\end{tabular}

Fig. 2. Effect of auxin transport inhibitors on pseudonodule formation on wild-type Medicago truncatula A17 21 days after treatment with different concentrations of N-(1-naphthyl)phthalamic acid (NPA) and 2,3,5-triiodobenzoic acid (TIBA). Asterisk (*) indicates significant difference between the two treatments by $t$ test $(P<0.001)$. Error bars represent standard error among pseudonodule-forming plants within a particular treatment $(n=40$ plants/treatment). 
The most striking feature of the expression profile is that 58 of the 64 genes show opposite directions of transcriptional change in response to ATI at 1 and 7 daa, compared with responses to $S$. meliloti. These 58 genes are in two clusters, I and II: those transcripts that are upregulated in response to ATI at early time points are downregulated in response to bacteria (cluster I) and vice versa (cluster II). As described below, at later time points, these transcripts are regulated similarly in response to both ATI and to bacteria. Cluster III includes transcripts that are expressed similarly in response to both ATI and to bacteria.

TC in cluster I (46 TC) are upregulated in response to $S$. meliloti 1021 while downregulated at early time points in one or both ATI. By 21 days after treatment, these 46 TC are regulated in the same direction in response to both $S$. meliloti 1021 and ATI. The set includes Rhizobium spp.-induced peroxidase (Rip1), a known marker for the early stages of rhizobial infection (Cook et al. 1995), and others encoding functions in oxida- tive stress, pathogenesis, transport, transcription, cell wall modification, hormone response, carbohydrate metabolism, signaling, energy metabolism, or nodulation.

The 13 TC in cluster II are downregulated in response to $S$. meliloti at all time points; they are transiently upregulated in response to ATI at 1 daa but then strongly downregulated by 7 and 21 daa. This set of genes includes several predicted to have roles in pathogenesis (Fig. 4).

The smallest group, cluster III, shows upregulation in both true nodules and pseudonodules. Among these TC, one is predicted to encode a transcription factor belonging to the AP2/ ERF family, and has been shown previously to be required for formation of functional nitrogen-fixing nodules (Vernié et al. 2008).

Taken together, these data indicate that some ATI-induced pseudonodulation responses are initially opposite to then, by 21 days, converge with those of Sinorhizobium spp.-induced

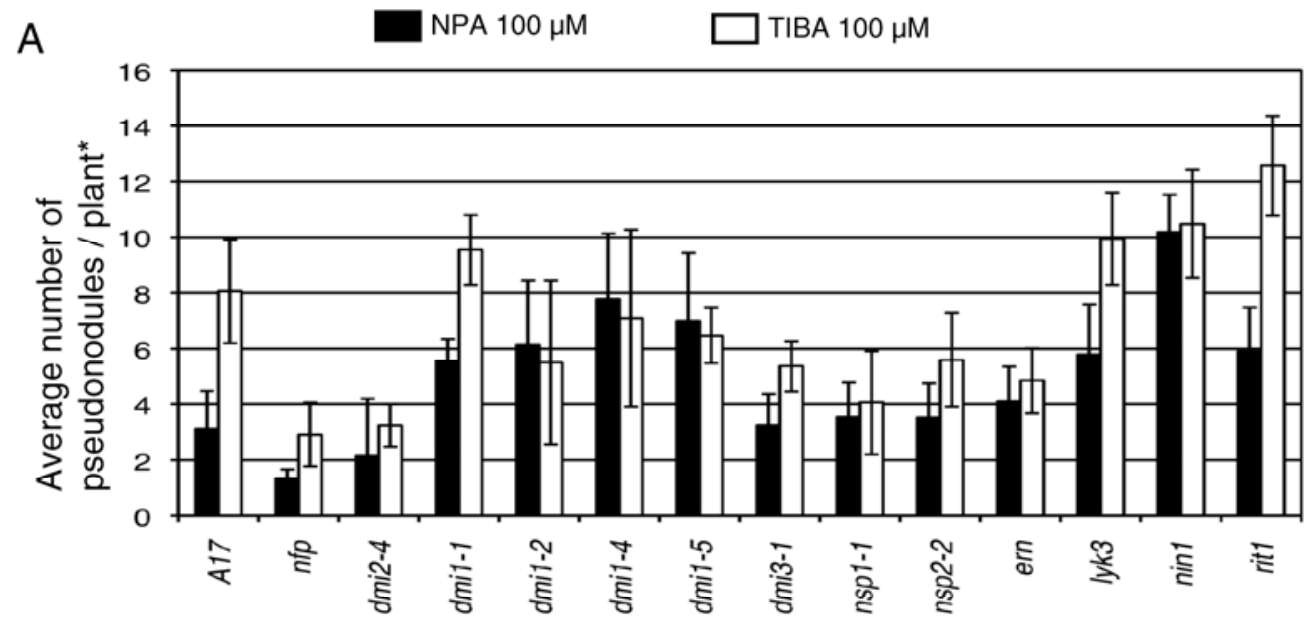

\begin{tabular}{|l|c|c|c|c|c|c|c|c|c|c|c|c|c|c|c|}
\hline \multirow{2}{*}{$\begin{array}{l}\text { Plants with } \\
\text { pseudonodules } \\
(\%)\end{array}$} & $\frac{\nwarrow}{乙}$ & 55 & 16 & 18 & 95 & 53 & 70 & 27 & 61 & 55 & 50 & 54 & 65 & 98 & 83 \\
\cline { 2 - 13 } & $\stackrel{\nwarrow}{\models}$ & 83 & 49 & 56 & 100 & 52 & 48 & 85 & 67 & 53 & 55 & 68 & 70 & 98 & 83 \\
\hline
\end{tabular}

B

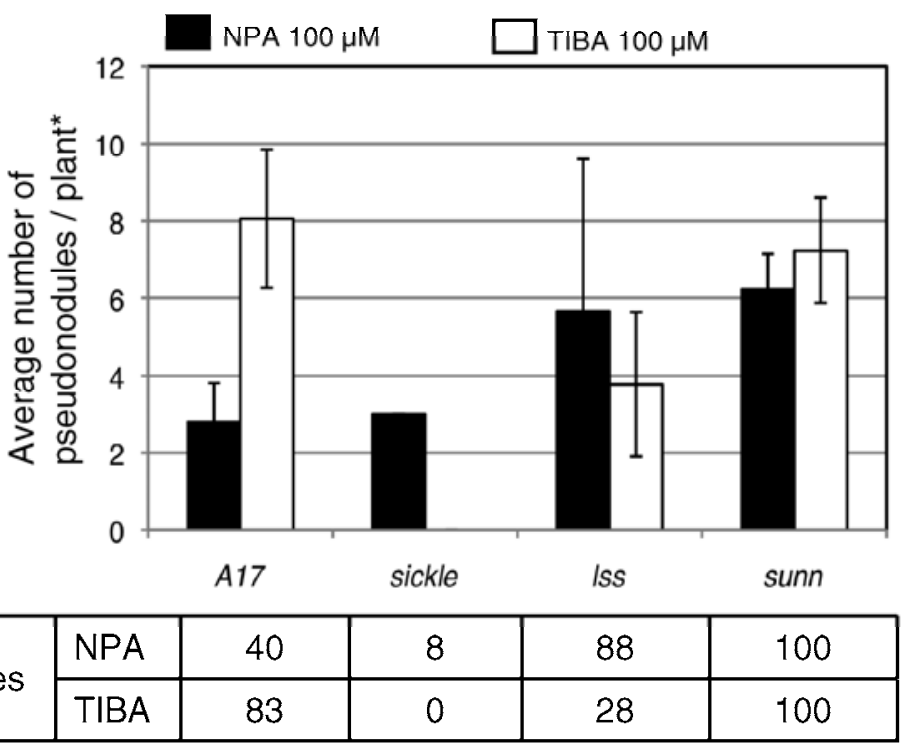

Fig. 3. A, Response of Medicago truncatula mutants to treatment with $100 \mu \mathrm{M} \mathrm{N}$-(1-naphthyl)phthalamic acid (NPA) or 100 $\mu \mathrm{M} 2,3,5$-triiodobenzoic acid (TIBA). B, Response of supernodulators roots to treatment with $100 \mu \mathrm{M}$ NPA or $100 \mu \mathrm{M}$ TIBA. Error bars represent standard error of plants that formed pseudonodules among 40 plants. 
root events. The responses that differ at early time points may represent bacterial-specific modulation of gene expression.

Comparison of 21-day gene expression patterns in normal nodules, empty nodules, and pseudonodules.

To identify genes that may be involved in nodule organogenesis, we compared 21-day gene expression profiles from WT nodules (NOD-DSS), ATI-elicited pseudonodules (ATI-
DSS), and $e x o A^{-}$nodules. The inclusion of the 21-dai $e x o A^{-}$ nodule transcript set made for a more stringent comparison of nodule-like structures per se. Using dChip ( $\mathrm{Li}$ and Wong 2001a,b), we identified 21 TC that showed differential expression compared with buffer controls for all three data sets (Fig. 5). The microarray expression data were validated by quantitative reverse-transcription polymerase chain reaction (RT-PCR) on RNA isolated from roots inoculated with $S$.

A

\begin{tabular}{|c|c|c|c|l|}
\hline Cluster & Rm1021 & NPA \& TIBA at 1 and 7daa & \# TCs & Notes \\
\hline$I$ & $\uparrow$ (up-regulated) & $\downarrow$ & 46 & TC107914 $\downarrow$ in Rm 1021 and ATIs \\
\hline II & $\downarrow$ (down-regulated) & $\uparrow 1$ dai $-\downarrow 7$ and 21daa & 13 & TC120528 $\downarrow$ at 1daa $-\uparrow$ at 21 daa \\
\hline III & $\uparrow$ & $\uparrow$ & 5 & All $\uparrow$ \\
\hline
\end{tabular}

B
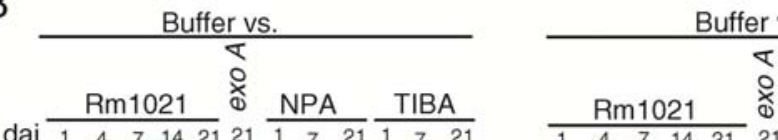

uffer vs.

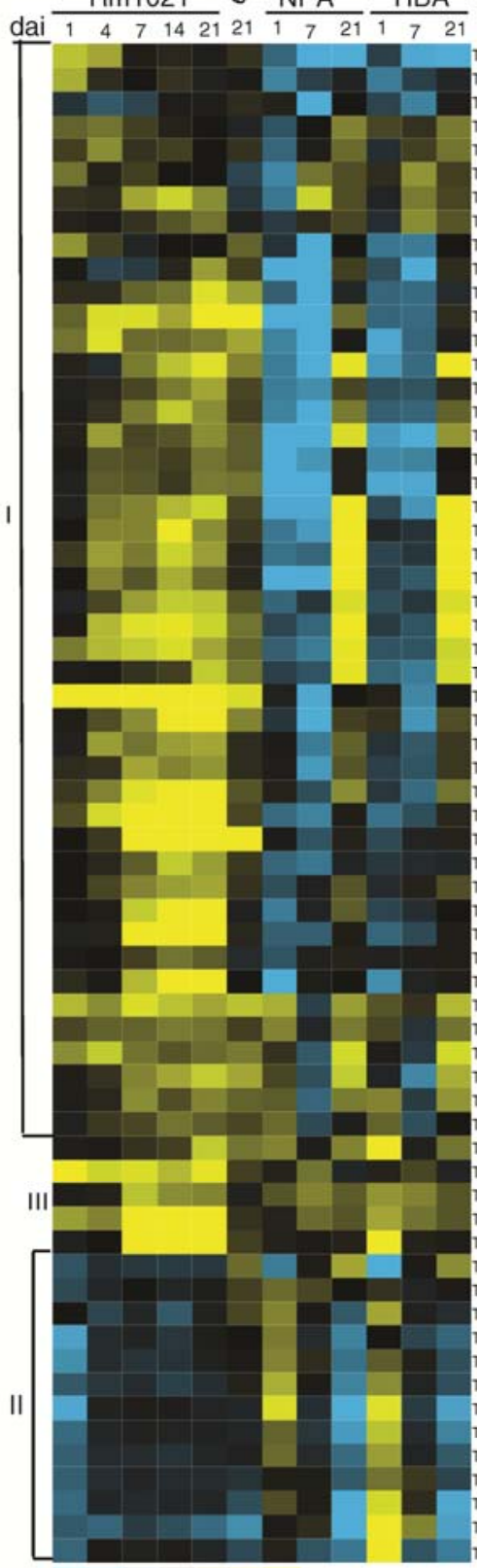

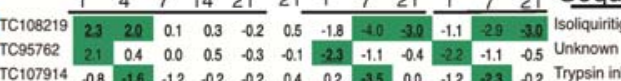

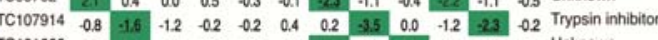

$\begin{array}{lllllllllllllll}\mathrm{TC} 101666 & 1.2 & 14 & 0.7 & 0.2 & 0.0 & -0.4 & -1.5 & 0.0 & 1.6 & 0.8 & 0.5 & 1.5 & \text { Unknown }\end{array}$

$\begin{array}{llllllllllllll}\text { TC110501 } & 0.7 & 1.2 & 0.5 & 0.7 & 0.0 & 0.5 & -1.8 & -0.2 & 1.3 & -0.7 & 0.7 & 1.4 & \text { Sulfate transporter }\end{array}$

$\begin{array}{llllllllllllllll}\text { TC100524 } & 14 & 02 & 0.7 & 0.0 & 0.0 & -12 & -24 & 1.4 & 0.9 & 0.4 & 18 & 0.7 & \text { Alpha-expansin } 3\end{array}$

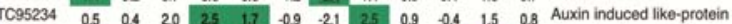

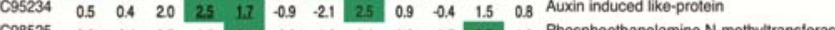

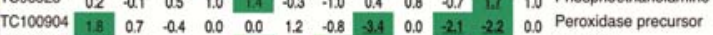

\begin{tabular}{llllllllll|l|l|l|l|l|l} 
IC100904 & 1.8 & 0.7 & -0.4 & 0.0 & 0.0 & 1.2 & -0.8 & -3.4 & 0.0 & -2.1 & -2.2 & 0.0 & Peroxidase \\
TC100160 & -0.1 & -1.2 & -1.0 & 0.3 & 1.9 & 0.7 & -3.7 & -5.3 & 0.7 & -1.4 & -3.5 & 0.4 & Narbonin
\end{tabular}

$\begin{array}{lllllllllllllllll}\mathrm{rC} 108074 & 0.4 & 0.4 & 12 & 1.4 & 2.8 & 1.9 & -1.7 & -5.2 & -0.5 & -1.8 & -1.9 & -0.6 & \text { Lipid binding }\end{array}$

$\begin{array}{llllllllllllll}\text { rC107261 } & 12 & 27 & 27 & 20 & 3.1 & 3.0 & -3.7 & -5.8 & 1.3 & -1.8 & -1.9 & 0.4 & \text { Peroxidase precursor (RIP1) }\end{array}$

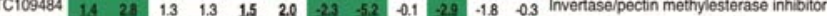

$\begin{array}{llllllllllllllll}\text { TC106553 } & 02 & -0.6 & 1.5 & 23 & 28 & 1.6 & -22 & 58 & 29 & -27 & .19 & 3.1 & \text { Cationic Peroxidase (PNC1) }\end{array}$

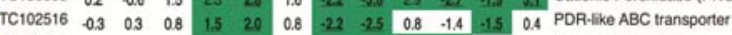

$\begin{array}{llllllllllllllll}\text { TC97623 } & -0.2 & 0.5 & 1.5 & 24 & 1.7 & 0.7 & -2.3 & -1.2 & 1.5 & -1.7 & -1.3 & 1.2 & \text { Peroxidase precursor }\end{array}$

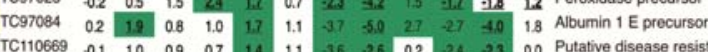

$\begin{array}{ccccc}\text { TC110669 } & 0.1 & 10 & 0.9 & 0.7 \\ \text { TC98442 } & 0.3 & 11 & 10 & 0.5\end{array}$

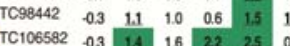

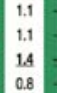

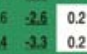

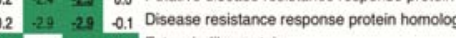

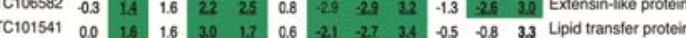

$\begin{array}{llllllllllllllll}\text { TC98205 } & 0.6 & 1.2 & 1.5 & 2.5 & 1.9 & 0.3 & -2.0 & -1.8 & 3.8 & -1.2 & -0.9 & 3.5 & \text { Unknown }\end{array}$

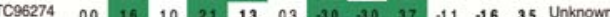

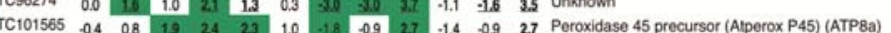

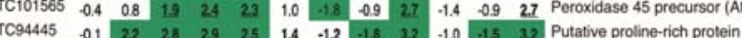

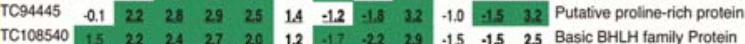

\begin{tabular}{l|lllll|l|l|l|l|l|l|l|l|l|l|l} 
TC108540 & 1.5 & 22 & 24 & 27 & 20 & 1.2 & -1.7 & -22 & 2.9 & -1.5 & -1.5 & 2.5 & Basic BHLH family Pro \\
TC106349 & -02 & -0.1 & 0.5 & 0.7 & 24 & 1.4 & -1.1 & -1.5 & 2.9 & -1.8 & -22 & 2.5 & Chitinase class It
\end{tabular}

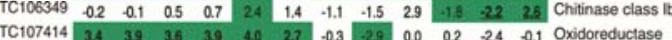

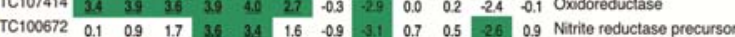

$\begin{array}{llllllllllllllll}\mathrm{r} C 107148 & -03 & 19 & 14 & 19 & 20 & 0.4 & -0.1 & -22 & 12 & -0.8 & -1.5 & 0.6 & \text { Root vegetative storage protein precursor }\end{array}$

$\begin{array}{llllllllllllll}\text { TC107795 } & 0.4 & 0.5 & 20 & 1.6 & 1.8 & 0.4 & -0.2 & -27 & 1.0 & -1.1 & -1.5 & 0.6 & \text { Thioredoxin s? }\end{array}$

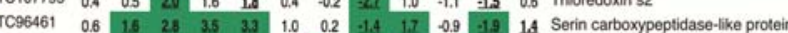

\begin{tabular}{ll|llll|l|l|l|l|l|l|l|l|l} 
TC96461 & 0.6 & 1.6 & 2.8 & 3.5 & 3.3 & 1.0 & 0.2 & -1.4 & 1.7 & -0.9 & -1.9 & 1.4 & Serin carboxypeptidase-like prote \\
TC99324 & 0.9 & 26 & 4.0 & 3.3 & 3.9 & 0.8 & -1.9 & -2.3 & 0.1 & -2.0 & -1.4 & 0.3 & Putative defensin AMP1 protein
\end{tabular}

\begin{tabular}{lllllll|ll|l|llll} 
TC99324 & 0.9 & 2.6 & 4.0 & 3.3 & 3.9 & 0.8 & -1.9 & -2.3 & 0.1 & -2.0 & -1.4 & 0.3 & Putative detensi \\
TC94518 & 0.0 & 0.6 & 6.1 & 6.4 & 6.5 & 4.2 & -0.1 & -1.5 & 0.2 & -1.3 & -0.4 & 0.2 & N8 protein
\end{tabular}

\begin{tabular}{llllllllll|lllll} 
rC108512 & 0.0 & 0.3 & 1.1 & 2.4 & 1.9 & 0.6 & -1.8 & -2.1 & -0.4 & -0.9 & -0.6 & -0.5 & Ethylene-responsive element binding protein 1
\end{tabular}

$\begin{array}{llllllllllllll}\text { TC99833 } & 0.0 & 0.8 & 1.6 & 1.9 & 2.0 & 0.5 & -1.4 & -0.3 & 1.0 & -0.6 & 0.2 & 0.9 & \text { Leucine rich repeat transmembrane protein }\end{array}$

$\begin{array}{lllllllllllllll}\text { TC108704 } & 0.0 & 0.1 & 24 & 3.5 & 32 & -0.3 & -22 & -0.4 & 1.1 & -1.2 & -0.7 & 0.0 & \text { MtN21-like protein }\end{array}$

\begin{tabular}{lllllllll|llllll} 
TC95535 & -0.3 & 0.2 & 3.9 & 4.8 & 3.6 & 0.3 & -1.7 & -1.7 & 0.1 & -1.8 & -1.3 & 0.1 & Unknown
\end{tabular}

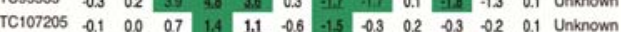

$\begin{array}{lllllllllllllllll}\text { TC95933 } & 0.4 & -0.1 & 22 & 3.5 & 30 & 0.0 & -4.5 & 0.1 & 0.0 & -25 & -0.4 & 0.1 & \text { Unknown }\end{array}$

\begin{tabular}{l|llllll|c|c|c|c|ccc} 
TC95933 & 0.4 & -0.1 & 22 & 3.5 & 3.0 & 0.0 & -4.3 & 0.1 & 0.0 & -2.5 & -0.4 & 0.1 & Unknown \\
TC 117803 & 22 & 1.7 & 2.7 & 2.3 & 20 & 2.3 & 2.1 & -1.1 & 1.9 & 1.0 & 0.5 & 22 & Ferritin
\end{tabular}

$\begin{array}{lllllllllllllll}\text { TC } 93938 & 0.8 & 1.2 & 1.2 & 1.5 & 1.4 & 0.7 & 1.6 & -0.5 & 1.5 & 0.8 & -0.8 & 14 & \text { Phi- } 1 \text { protein }\end{array}$

$\begin{array}{llllllllllllll}\text { TC126340 } & 1.7 & 24 & 1.4 & 1.0 & 1.3 & 1.5 & 0.5 & -1.6 & 2.6 & -0.2 & -1.0 & 2.5 & \text { DVL3 }\end{array}$

$\begin{array}{lllllllllllllll}\text { TC115158 } & 0.1 & 0.5 & 1.6 & 20 & 24 & 20 & 0.8 & -14 & 24 & -0.4 & -24 & 2.1 & \text { Alpha-fucosidase }\end{array}$

$\begin{array}{llllllllllllllll}\text { TC109279 } & -0.2 & 0.3 & 1.7 & 0.9 & \text { t. } & 1.2 & 1.1 & -1.8 & 1.5 & 1.6 & -1.0 & 1.8 & \text { Unknown }\end{array}$

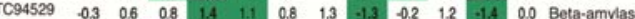

$\begin{array}{llllllllllllllll}\text { TC107287 } & -0.2 & -0.1 & 0.5 & 0.7 & 2.4 & 1.4 & 1.6 & -0.2 & 1.6 & 0.6 & -0.3 & 1.4 & \text { Hexose transporter }\end{array}$

$\begin{array}{lllllllllllllllll}\text { TC96874 } & -0.2 & -0.1 & 0.5 & 0.7 & 2.4 & 1.4 & 1.6 & -0.2 & 1.6 & 1.2 .6 & -0.3 & 1.4 & \text { Hexose transp } \\ \text { TC } & 2.2 & 2.2 & 2.9 & 0.7 & 0.2 & 1.4 & -0.5 & 0.2 & 0.8 & -0.4 & \text { Unknown }\end{array}$

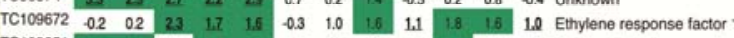

\begin{tabular}{l|lll|lllllllllll} 
rC100851 & 1.2 & 1.6 & 40 & 50 & 47 & 0.5 & 0.2 & 1.3 & 1.0 & 20 & 1.4 & 1.0 & Multifunctional aquaporin
\end{tabular}

$\begin{array}{lllllllllllllll}\text { IC }_{10035} & 0.3 & 0.0 & 32 & 5.1 & 4.1 & 0.7 & 0.2 & -0.1 & 0.2 & 3.4 & 0.2 & 0.1 & \text { Unknown }\end{array}$

\begin{tabular}{ll|lllllllllllll} 
TC120528 & -1.5 & -0.7 & -0.9 & -1.0 & -0.9 & 1.3 & -2.2 & 0.1 & 2.0 & -3.1 & -0.1 & 1.7 & Terpene synthase
\end{tabular}

$\begin{array}{llllllllllllll}C 96672 & -13 & -0.5 & 0.0 & -0.5 & -0.2 & 0.7 & 1.3 & 0.8 & 0.0 & 0.5 & -0.4 & -0.1 & \text { Adidie glucanase }\end{array}$

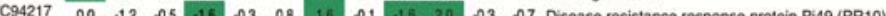

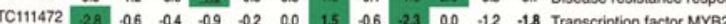

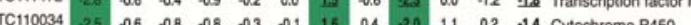

$\begin{array}{llllllllllllllll}\text { IC110034 } & -2.5 & -0.6 & -0.8 & -0.8 & -0.3 & -0.1 & 1.6 & 0.4 & -2.0 & 1.1 & 0.2 & -1.4 & \text { Cytochrome P450 }\end{array}$

$\begin{array}{llllllllllllll}-0.9 & -0.6 & -1.1 & -0.7 & 0.2 & 2.1 & -0.1 & -2.3 & 1.7 & -0.4 & -1.4 & \text { isollavone-7-0-methytransterase } 9\end{array}$

$\begin{array}{lllllllllllllll}\text { TC101519 } & -29 & -0.3 & -0.2 & -0.2 & -0.4 & -0.5 & 2.7 & -0.7 & -4.0 & 28 & -1.0 & -28 & \text { Patatin-like protein } 1\end{array}$

$\begin{array}{lllllllllllllll}\text { TC108403 } & -19 & -0.5 & -0.3 & -0.4 & -0.3 & -0.5 & 1.2 & -0.9 & -2.7 & 2.3 & -0.6 & -2.3 & \text { Protease inhibitor 2 }\end{array}$

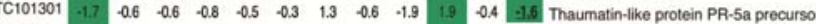

$\begin{array}{lllllllllll}\mathrm{r} 94478 & -1.7 & -0.7 & -0.4 & -0.6 & -0.6 & -0.8 & 0.1 & 0.1 & -1.6 & 1\end{array}$

$\begin{array}{lllllllllll}\text { TC108442 } & -1.9 & -0.5 & -0.6 & -0.5 & -0.5 & -1.4 & 0.9 & 0.1 & -3.1\end{array}$

$0.6 \quad 12$ Perakine reductase

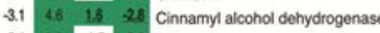


meliloti exo $A^{-}$versus control buffer-treated roots (Table 1). In most of the nine TC tested, the change in transcript abundance observed by Affymetrix chip correlated with real time RT-PCR results.

The $21 \mathrm{TC}$ common to the $e x o A^{-}$, WT, and ATI data sets fell into three clusters based on expression patterns (Fig. 5). Cluster I, composed of 16 TC upregulated in all treatments, have putative involvement in cellular transport, development, pathogenesis, cell wall integrity and modification, signaling, or secondary metabolism (Van Eldik et al. 1996; Wen et al. 2004; Woo et al. 1999). Cluster II, one TC annotated as terpene synthase, is downregulated at all time points tested during symbiosis with WT $S$. meliloti 1021 but upregulated in response to $e x o A^{-}$and ATI at 21 days. Cluster III, four TC downregulated in all treatments, included one annotated for disease resistance and another (TC119939) with significant homology to nodulin MtN21.
TC119939 was consistently downregulated in our experiments, a difference with MtN21 which is reported to be an upregulated gene (Gamas et al. 1996).

Our discovery that $s k l$ mutants are defective in ATI-induced pseudonodulation prompted us to study expression in skll-1 roots treated with ATI. We analyzed differential expression in skl1-1 roots at 21 days after treatment with NPA, TIBA, or $S$. meliloti compared with buffer-treated control roots. TIBA elicited significant transcriptional changes in only two TC compared with buffer-treated roots (Fig. 6). NPA, which elicits limited pseudonodules on skll-1, stimulated expression of 26 sequences in common with bacterial nodules (Fig. 6). In both skll-1 and WT M. truncatula, TC121823 (MtN13) and TC132384 (cycloartenol synthase) showed the strongest upregulation in response to $S$. meliloti 1021 and to NPA (Figs. 6 and 5 , respectively). The robustness of expression by these two

Fig. 4. Sequences differentially regulated in roots inoculated with Sinorhizobium meliloti wild-type (WT) or mutant bacteria, or treated with auxin transport inhibitors. A, Summary of the three main clusters of genes regulated similarly in response to each treatment. B, The 64 genes discussed in the text, organized by the clusters summarized above. Color representation of the $\log _{2}$-fold change is shown on the left, with brackets marking the three main clusters identified using Cluster 3.0; yellow indicates upregulation and blue indicates downregulation. At right, the first column of the table indicates the tentative consensus sequence (TC) number in MTGI 8.0. Columns 2 to 13 show the $\log _{2}$-fold change in expression level from pairwise comparisons between WT plants exposed to buffer and to WT bacteria at 1, 4, 7, 14, and 21 days after inoculation with live bacteria (dai) (columns 2 to 6 , respectively); bacterial mutant exoA 21 dai (column 7); $200 \mu \mathrm{M} \mathrm{N}$-(1-naphthyl)phthalamic acid (NPA) treatment at 1, 7, and 21 dai (columns 8 to 10, respectively); and $200 \mu \mathrm{M}$ TIBA treatment at 1, 7 , and 21 dai (columns 11 to 13, respectively). Table cells colored in green indicate genes predicted by dCHIP to change transcript levels greater than or equal to twofold. Numbers in bold and underlined indicate genes predicted by significance analysis of microarrays to change transcript levels greater than or equal to twofold. Columns 14 and 15 show the predicted function of the identified TC using tblastx and their e-value.

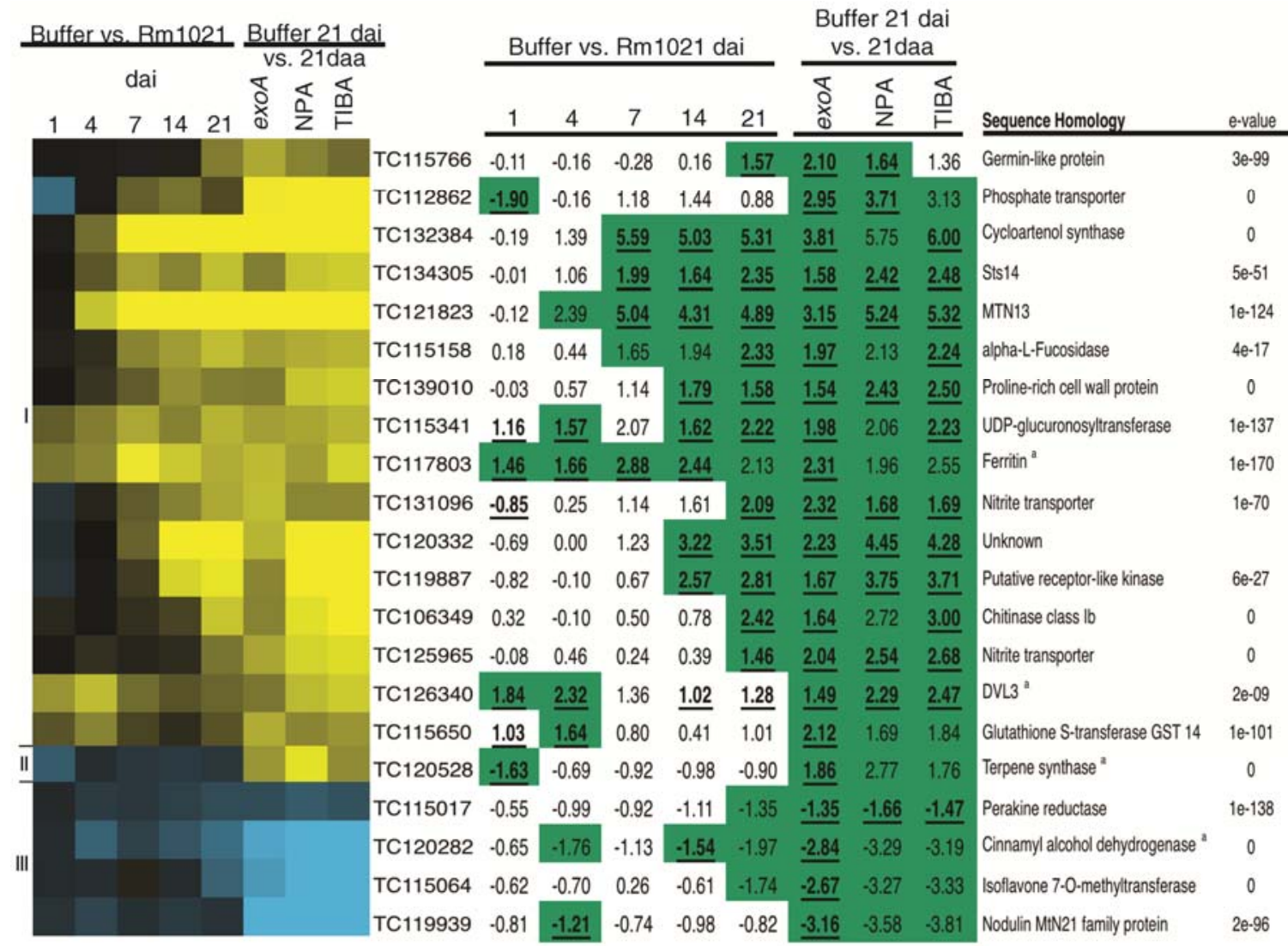

Fig. 5. Sequences with similar pattern of regulation in roots inoculated with wild-type (WT) or mutant Sinorhizobium meliloti bacteria, or treated with auxin transport inhibitors. . Color representation of the $\log _{2}$-fold change is shown on the left, with brackets marking the three main clusters identified using Cluster 3.0; yellow indicates upregulation and blue indicates downregulation. The first column of the table indicates the tentative consensus sequence (TC) number in MTGI 8.0. Columns 2 to 9 show the $\log _{2}$-fold change in expression level from pairwise comparisons between WT plants exposed to buffer and to WT bacteria at $1,4,7,14$, and 21 days after inoculation with live bacteria (dai) (columns 2 to 6 , respectively); bacterial mutant exoA (column 7); $200 \mu \mathrm{M}$ N-(1naphthyl)phthalamic acid (NPA) (column 8); or $200 \mu \mathrm{M}$ 2,3,5-triiodobenzoic acid (TIBA) (column 9). In the table at right, cells colored in green indicate changes in transcript level calculated by dCHIP as greater than or equal to twofold. Numbers in bold and underlined indicate changes calculated similarly by significance analysis of microarrays. Columns 10 and 11 indicate the best protein match and e-value using tblastx. 
TC in varied nodule-like growths suggests that they play a role in nodule organogenesis.

In vivo expression and function of upregulated sequences.

To assess spatial nodule-specific expression of TC upregulated at 21 daa by both NPA and TIBA, we created $\beta$-glucuronidase (GUS) fusions to promoters of at least one TC from each of the following functional categories: plant development or pathogenesis (Sts14, TC134305), cell wall modification $(\alpha-$

Table 1. Verification of expression patterns of nine tentative consensus sequences (TC) by using real-time reverse-transcription polymerase chain reaction (RT-PCR)

\begin{tabular}{lcc}
\hline & \multicolumn{2}{c}{ Log $_{2}$ fold change } \\
\cline { 2 - 3 } TC number & RT-PCR & Chip \\
\hline TC121823 & 3.54 & 3.15 \\
TC132384 & 3.45 & 3.81 \\
TC131096 & 3.35 & 2.32 \\
TC115341 & 2.54 & 1.98 \\
TC117107 & 2.50 & 1.64 \\
TC126340 & 1.77 & 1.49 \\
TC125965 & 0.96 & 2.04 \\
TC139010 & 0.64 & 1.54 \\
TC115158 & 0.28 & 1.97 \\
\hline
\end{tabular}

a Samples are from roots harvested 21 days after inoculation with $S$. meliloti exo $A^{-}$compared with buffer-inoculated controls.
L-fucosidase, TC115158), transporters (Ferritin, TC117803, and nitrate transporter, TC131096), and plant development (DVL3, TC126340). Transgenic roots were constructed for each of these, and gene reporter activity was assessed in WT nodules (Fig. 7). GUS staining of these transgenics indicated that the microarray experiments have primarily identified nodule-expressed transcripts.

We tested whether these genes were required for nodule organogenesis. We used RNA interference (RNAi) to silence each of the 17 genes that are upregulated in response to both ATI and S. meliloti (Fig. 5, clusters I and II) and assessed their phenotype. The degree of silencing in nodulated roots for each RNAi construct was determined by real-time RT-PCR.

As a positive control, we silenced SICKLE (SKL); mutations in this gene should result in supernodulation (Penmetsa et al. 2008). Roots transformed with the SKL RNAi construct showed a significant decrease in both expression of the $S K L$ gene (Fig. 8 ) and the expected increase in nodule number (Table 2).

Among the transgenic RNAi constructs for the 17 cluster I and II sequences, 11 showed some silencing and 8 of these 11 showed $>50 \%$ reductions in expression (Fig. 8). The efficiency of nodulation was significantly affected in four constructs in which genes were substantially silenced: TC115158 ( $\alpha$-L-fucosidase), TC121823 (MtN13), TC131096 (nitrate transporter), and 120332 (unknown). No root phenotype was observed in any of these four constructs. The data indicate that these genes

\begin{tabular}{|c|c|c|c|c|c|c|c|c|}
\hline \multicolumn{3}{|c|}{ Buffer vs. } & & \multicolumn{3}{|c|}{ Buffer vs. } & \multirow[b]{2}{*}{ Sequence homology } & \multirow[b]{2}{*}{ e-value } \\
\hline 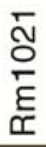 & $\frac{\nwarrow}{\text { ¿ }}$ & 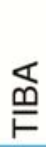 & & 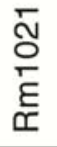 & $\frac{\nwarrow}{2}$ & $\stackrel{®}{\stackrel{\complement}{\models}}$ & & \\
\hline & & & TC126650 & 0.7 & -1.7 & -3.1 & Salt-tolerance protein & $6 e-74$ \\
\hline & & & TC114048 & 0.4 & -1.2 & -3.0 & MYB transcription factor & $9 e-95$ \\
\hline & & & TC125718 & 2.9 & 3.0 & 0.9 & Gibberellin regulated protein & $1 e-48$ \\
\hline & & & TC141258 & $\underline{2.3}$ & 2.5 & 0.7 & Proline-rich cell wall protein & $3 e-58$ \\
\hline & & & TC119887 & $\overline{1.8}$ & $\underline{2.0}$ & 0.4 & Putative receptor-like kinase ${ }^{a}$ & $3 e-27$ \\
\hline & & & TC132384 & $\underline{5.2}$ & 4.7 & 1.3 & Cycloartenol synthase ${ }^{a}$ & 0 \\
\hline & & & TC139010 & $\underline{1.9}$ & 1.7 & 0.5 & Proline-rich cell wall protein ${ }^{a}$ & 0 \\
\hline & & & TC121823 & $\underline{5.5}$ & 5.0 & 1.9 & MtN13 protein ${ }^{a}$ & $1 e-124$ \\
\hline & & & TC140545 & $\underline{3.5}$ & 2.8 & 0.7 & MtN5 protein precursor & $2 e-134$ \\
\hline & & & TC94445 & $\overline{3.2}$ & 2.6 & 0.5 & Putative proline-rich protein & $3 e-22$ \\
\hline & & & TC120332 & $\overline{2.3}$ & $\underline{2.0}$ & 0.3 & Unknown ${ }^{a}$ & \\
\hline & & & TC124043 & 2.4 & $\overline{2.1}$ & 0.3 & Unknown & $9 e-46$ \\
\hline & & & TC106582 & $\underline{\underline{2.3}}$ & 2.2 & 0.3 & Extensin-like protein & $3 e-47$ \\
\hline & & & TC130867 & $\underline{2.5}$ & 2.0 & 0.0 & BHLH transcription factor & $6 e-170$ \\
\hline & & & TC129646 & $\underline{2.5}$ & $\underline{2.9}$ & 0.0 & MtN3 protein precursor & 0 \\
\hline & & & TC128442 & $\overline{1.7}$ & $\overline{2.6}$ & 0.9 & Unknown & $3 e-171$ \\
\hline & & & TC98205 & $\underline{2.0}$ & 2.9 & 0.5 & Unknown & \\
\hline & & & TC118105 & $\underline{2.5}$ & 3.5 & 0.9 & Apyrase-like protein & 0 \\
\hline & & & TC96274 & $\overline{1.8}$ & 2.8 & 0.7 & Unknown & 0 \\
\hline & & & TC94274 & $\overline{1.8}$ & 2.0 & 1.1 & Thaumatin-like protein & $2 e-162$ \\
\hline & & & TC101541 & $\underline{2.4}$ & 2.6 & $\overline{1.0}$ & Lipid transfer protein & $1 e-21$ \\
\hline & & & TC118509 & $\overline{2.6}$ & 2.7 & 1.3 & Peroxidase 1 & $1 e-142$ \\
\hline & & & TC126914 & $\underline{3.2}$ & 1.9 & 0.2 & Predicted protein & $9 e-31$ \\
\hline & & & TC121688 & $\overline{3.1}$ & 1.7 & 0.4 & Endo-1,4-beta-glucancase & $3 e-87$ \\
\hline & & & TC119441 & $\underline{3.6}$ & 1.7 & 0.3 & Unknown & $7 e-85$ \\
\hline & & & TC119196 & $\overline{4.3}$ & 2.2 & 0.4 & Unknown & $7 e-10$ \\
\hline & & & TC100658 & $\overline{4.3}$ & 1.6 & 0.1 & Unknown & \\
\hline & & & TC131578 & $\overline{4.4}$ & 1.8 & -0.2 & Unknown & $2 e-02$ \\
\hline
\end{tabular}

Fig. 6. Sequences with similar pattern of regulation in skl1-1 roots inoculated with wild-type (WT) Sinorhizobium meliloti bacteria, or treated with auxin transport inhibitors (ATI). Color representation of the $\log _{2}$-fold change is shown on the left; yellow indicates upregulation and blue indicates downregulation. The first column of the table indicates the tentative consensus sequence (TC) number in MTGI 8.0. Columns 2 to 4 show the $\log _{2}$-fold change in expression level from pairwise comparisons between WT plants exposed to buffer and to WT bacteria at 21 days after inoculation with live bacteria (dai) (column 2), $200 \mu \mathrm{M} \mathrm{N}$-(1-naphthyl)phthalamic acid (NPA) (column 3), or $200 \mu \mathrm{M}$ 2,3,5-triiodobenzoic acid (TIBA) (column 4). In the table, cells colored in green indicate changes in transcript level calculated by dCHIP as greater than or equal to twofold. Numbers in bold and underlined indicate changes calculated by significance analysis of microarrays. Columns 5 and 6 indicate the closest protein match and e-value using tblastx. Superscript a indicates TC differentially regulated also in the expression profile for A17 in response to $S$. meliloti 1021 and to both ATI. 
are required for normal nodulation efficiency and may have a role in nodule organogenesis. Those nodules that did form on gene-silenced transgenic roots appeared morphologically normal and were pink in color, suggesting that they were functional (Fix+) (Table 2). This may indicate that these transcripts are not required for later stages of nodule function, or that the low level of residual transcript is sufficient to accomplish the needed functions.

\section{DISCUSSION}

ATI-elicited pseudonodules and $S$. meliloti-induced nodules share common features.

As in M. sativa (Hirsch et al. 1989), M. truncatula responds to ATI treatment by forming pseudonodules. We compared this process to known features of nodule formation. During initial stages of the two processes, some transcriptional regulation differs for ATI-induced pseudonodules and true nodules but the two converge by 21 days. We derive the general conclusion that ATI-elicitation of pseudonodules does trigger the nodule morphogenesis and differentiation program. However, experiments using a series of $M$. truncatula $\mathrm{Nod}^{-}$mutants showed that the ATI-pseudonodule process bypasses early steps of NF signal transduction.

The exact mechanism by which ATI or cytokinins induce pseudonodule formation remains unknown. These plant growth substances are well known to affect cell differentiation and cell division in many diverse contexts. However, it is not clear why these treatments specifically provoke a nodule-like program of cell division and morphogenesis in legume roots. We can outline the general features of ATI-induced pseudonodule formation as follows.

\section{Transcriptional differences in $M$. truncatula roots between ATI and bacterial treatment.}

Comparisons of transcription patterns in S. meliloti-inoculated and ATI-treated roots identified genes that were differentially transcribed in both, as might be expected if morphogenesis
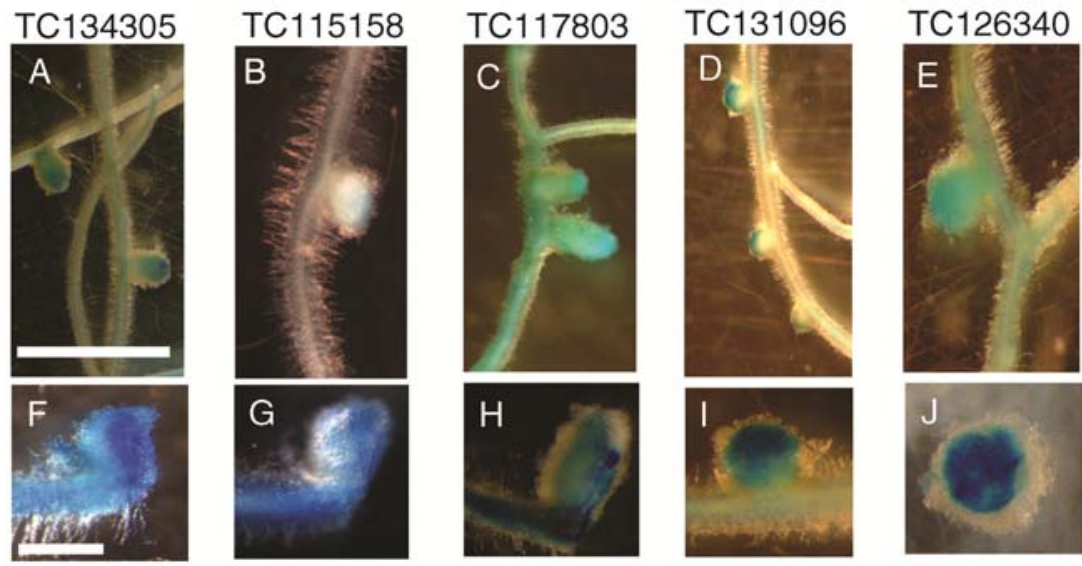

Fig. 7. Expression of tentative consensus sequence (TC) promoter fusions to $\beta$-glucuronidase (GUS). A to E, Expression in nodules at 21 days after inoculation (dai) with wild-type Sinorhizobium meliloti 1021. Scale bar $=1 \mathrm{~mm}$. F to J, Close-up hand section of GUS expression in nodules at 21 dai. Scale bar $=$ $250 \mu \mathrm{m}$.

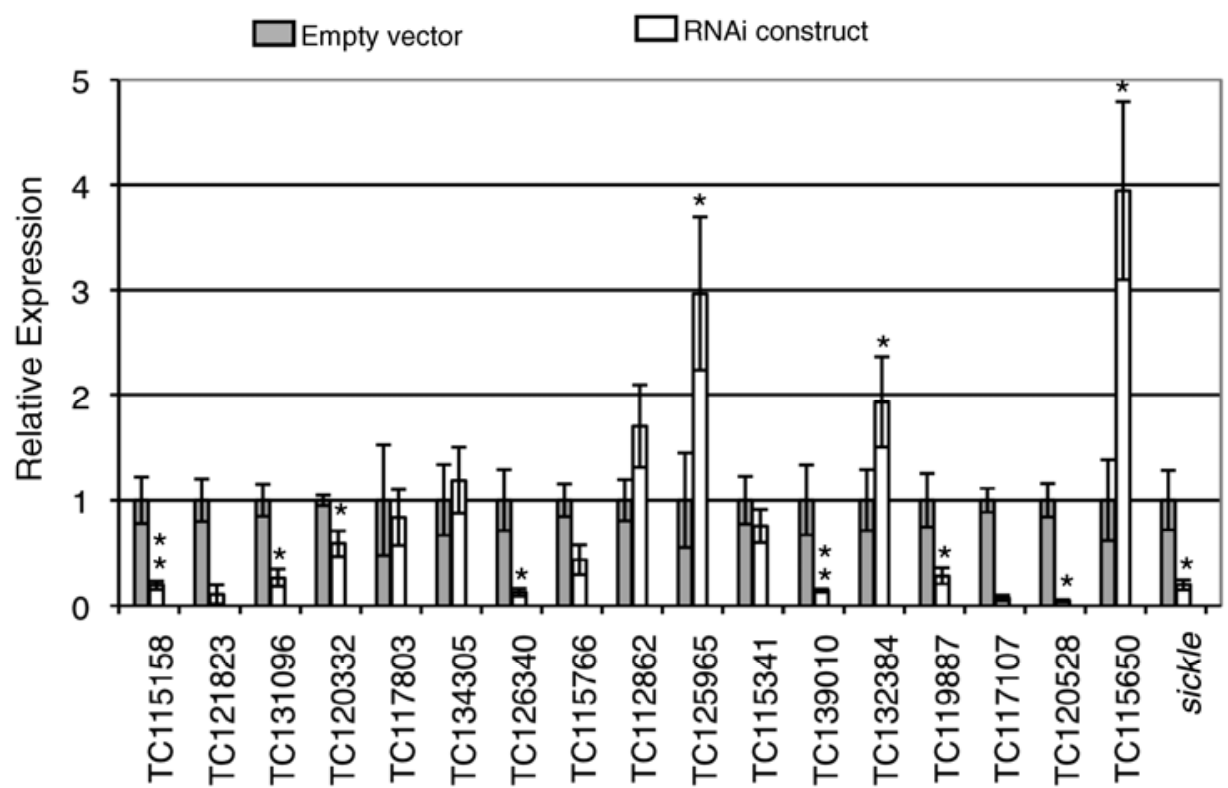

Fig. 8. Real-time reverse-transcription polymerase chain reaction (RT-PCR) analysis of genes targeted for silencing. Real-time RT-PCR was performed on Agrobacterium rhizogenes-transformed Medicago truncatula roots carrying either a control (empty RNA interference [RNAi] vector) or the corresponding RNAi construct. Histogram represents the average of three biological replicates normalized to the empty vector control. Error bars represent the standard error for three biological replicates; * and ** indicate significantly different by the $t$ test at $P<0.1$ or 0.2 , respectively. 
functions are common to both processes. Various sets of ATIDSS sequences overlap, with comparison made to sequences that are upregulated (Fig. 9A) or downregulated (Fig. 9B) in 21-dai nodules formed by WT and empty nodules formed by exoA $A^{-}$S. meliloti.

The sets of overlapping sequences show several noteworthy features. First, groups of sequences are coordinately regulated

Table 2. Nodulation response of RNAi-silenced plants inoculated with wild type S. meliloti $\mathrm{Rm} 1021$

\begin{tabular}{llcc}
\hline TC & \multicolumn{1}{c}{ Sequence homology } & $\begin{array}{c}\text { Average } \\
\text { number of } \\
\text { nodules/plant }\end{array}$ & $\begin{array}{c}\text { Number of } \\
\text { plants } \\
\text { evaluated }\end{array}$ \\
\hline 115158 & o-L-fucosidase & $4.1^{* *}$ & 14 \\
$121823^{\text {a }}$ & MtN13 & $4.2^{* *}$ & 63 \\
$131096^{\text {a }}$ & Nitrate transporter & $6.0^{* *}$ & 53 \\
120332 & Unknown & $6.0^{*}$ & 16 \\
117803 & Ferritin & 6.3 & 15 \\
134305 & Sts14 & 8.8 & 16 \\
126340 & DVL3 & 9.4 & 13 \\
115766 & Germin-like protein & 9.8 & 19 \\
112862 & Phosphate transporter & 9.9 & 15 \\
125965 & Nitrate transporter & 10.1 & 14 \\
115341 & UDP-glucuronosyltransferase & 10.5 & 13 \\
139010 & Proline-rich cell wall protein & 10.9 & 14 \\
132384 & Cycloartenol synthase & 12.7 & 23 \\
119887 & Putative receptor-like kinase & 12.7 & 15 \\
117107 & Chitinase class Ib & 13.8 & 13 \\
120528 & Terpene synthase & 14.1 & 15 \\
115650 & Glutathione $S$-transferase & 15.3 & 11 \\
sickle & $\ldots$ & $28.2^{* *}$ & 77 \\
EV & $\ldots$ & 11.2 & 100 \\
\hline
\end{tabular}

a Tentative consensus sequences (TC). EV = empty vector.

${ }^{\mathrm{b}}$ Results are pooled from two independent experiments (three independent experiments for TC121823 and TC131096); * and ** indicate significantly different by the $t$ test at $P<0.01$ or 0.001 , respectively. during ATI treatment. Some of them show the same expression timing in ATI response as in normal nodule development (Fig. 9A, group 4). Second, other genes displayed a quirk in the timing of transcription change: these were upregulated during early stages of bacteria-induced nodulation but downregulated in comparable stages of ATI-treatment, or vice versa (Fig. 9A, group 3 and B, group 3, respectively). This pattern was detectable at 1 and 7 dai with bacteria or ATI, at which times no pseudonodules are yet visible on roots.

Examples of the first group include sequences we found to be required for nodulation efficiency: TC121823 (MtN13), TC131096 (nitrate transporter), and TC120332 (unknown). Among the second group of sequences (that temporarily show an opposite direction of expression change) are TC106349 (annotated as chitinase class Ib) and TC115158 ( $\alpha$-L-fucosidase), which appear to be involved in nodule efficiency. We infer that genes in this second group share a set of control elements; further, these regulators are misdirected at early times after root treatment with ATI, then recover to act in parallel with nodule development by 21 days.

One scenario consistent with these observations is that opposing directions of gene expression for 1- and 7-daa ATItreated roots may occur because pseudonodules are delayed in their development compared with normal nodules, and that some regulators require that development get past a particular stage in order to trigger infection. In normal Sinorhizobium spp.-elicited nodules, a few host transcripts in nodules show opposing directions of expression if observed during the first hours, compared with later stages (G. Oldroyd, personal communication). It is possible that the ATI treatment traverses this developmental stage over many days, rather than hours. If this were the case, the search for a possible common regulatory network regulating this class of transiently opposite changes in expression may help relate the
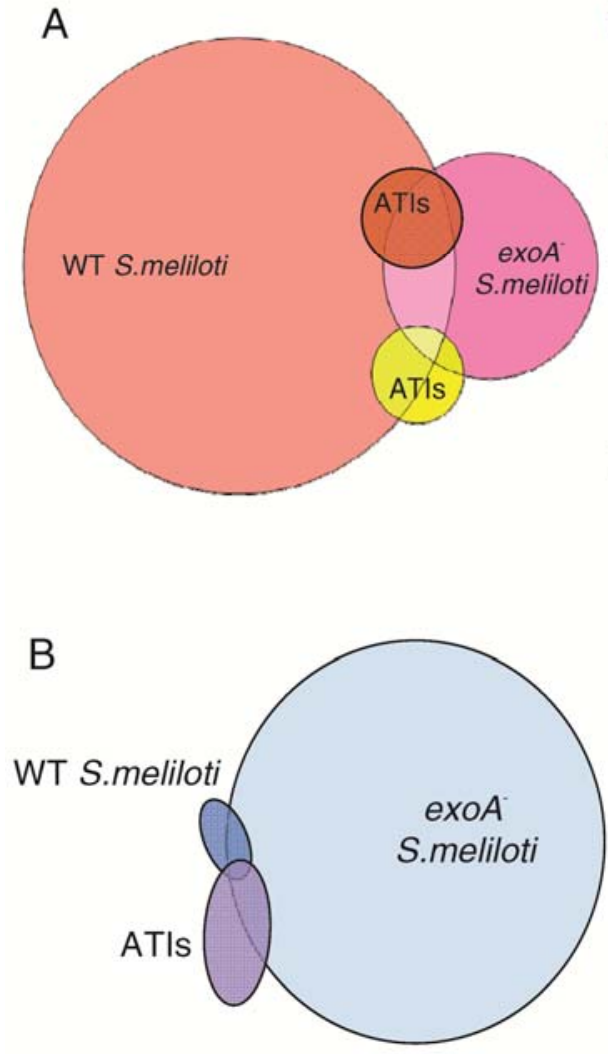

Group 1: 397 sequences up-regulated in 21 dai nodules formed by WT S. meliloti

Group 2: 98 sequences up-regulated in 21 dai empty nodules formed by exoA S. meliloti

Group 3: 18 sequences down-regulated in 1 and 7 daa pseudonodules and up-regulated by 21 daa. These sequences are in Cluster I

Group 4: 18 sequences up-regulated in parallel during normal nodule and ATI pseudonodule formation. These sequences are in Cluster III and Cluster I

Group 1: 4 sequences down-regulated in 21 dai nodules formed by WT S. meliloti

Group 2: 93 sequences down-regulated in 21 dai empty nodules formed by exoA $S$. meliloti

Group 3: 12 sequences up -regulated in 1 and 7 daa pseudonodules and down-regulated by 21 daa. Cluster II

Fig. 9. Auxin transport inhibitor (ATI) differential sequence set sequences on the background of sequences A, upregulated and B, downregulated at 21 days after inoculation with live bacteria (dai) in wild-type (WT) and empty nodules formed by Sinorhizobium meliloti Rm1021 and exoA $A^{-}$, respectively. 
action of ATI to intrinsic signals coming from the plant in very early stages of nodule formation.

A second possible model arises from considering that the set of genes with transiently opposite expression changes includes some that may be pathogenesis-related (Fig. 4, cluster II). These are depicted in Figure 9B, where they are compared with sequences that are downregulated in 21-dai nodules formed by WT and empty nodules formed by $e x o A^{-} S$. meliloti. It has been speculated that pathogenesis-related genes are suppressed in nodules due to signals (or masking of signals) coming from the bacteria (Jones et al. 2008). In pseudonodules, we found that some such genes are eventually downregulated despite the absence of any bacterial cells in the ATI treatment. Thus, at least some pathogenesis-related genes may be regulated via the nodule developmental program.

\section{Genes involved in formation}

\section{of nodules and pseudonodules are similarly regulated.}

At 21 days, gene expression profiles of ATI-elicited pseudonodules and WT- and $e x o A^{-}$-induced nodules revealed 21 TC that were either up- or downregulated in response to all treatments. These TC are predicted to have functions such as transport, pathogenesis response, signaling, development or cell wall integrity, and modification, which are categories plausibly related to the development and maintenance of nodule structure.

Whether such gene expression changes truly reflect important functions in nodule development-specifically, morphogenesis - can be inferred only through direct studies. Promoter fusions confirm nodule expression of genes with diverse predicted functions (Fig. 7). RNA-silencing studies of a set of representative genes showed that most of them are not uniquely required for nodule development. However, we identified four genes (TC115158, TC121823, TC131096, and TC120332) that are required for nodulation efficiency, as shown by phenotype of plant transgenics in which they were substantially silenced. Only one, TC121823, (MtN13) (Gamas et al. 1998), has previously been implicated in nodule organogenesis.

We speculate that the similar gene expression profiles of ATItreated and $S$. meliloti-inoculated roots at 21 days indicate that nodules and pseudonodules trigger common transcriptional networks by this time. The parallel regulation of these genes in nodules formed by $S$. meliloti (WT or exoA) and in pseudonodules formed by ATI implies they may play a role in nodule organogenesis. It would be interesting to test pseudonodule formation induced by ATI or exoA mutants in transgenic plants where these four constructs have been silenced in order to gather an understanding of the absolute mechanism of nodule organogenesis.

The list of genes highlighted in these studies may serve as a starting point to connect the role of plant hormones to either nodulation, nodule organogenesis, or both.

\section{ATI and nodule signaling genes.}

Supernodulation mutants lss and sunn did not show a superpseudonodulation phenotype. This implies that the number of pseudonodules formed is subject to some form of autoregulation. It is not surprising to consider some autoregulation of pseudonodule formation because feedback suppression of Rhizobium spp.-induced nodule formation has been previously reported by spontaneous nodules (Caetano-Anollés et al. 1990a) and by nodules induced by exopolysaccharide mutants (Caetano-Anollés et al. 1990b).

Another interesting result is the response of sunn mutants to NPA forming a higher number of pseudonodules per plant in all plants tested compared with WT (Fig. 3B). This is interesting in light of the fact that, in the sunn mutant, the supernodulation phenotype is explained by higher amounts of auxin loaded into the root compared with WT, leading to higher auxin levels in the zone of nodule initiation (van Noorden et al. 2006).

$M$. truncatula mutants affected in NF perception and signaling retain the ability to form pseudonodules in response to ATI. This implies that the machinery for ATI-stimulation of cell divisions and morphogenesis lies downstream of these early nod genes.

Madsen and associates (2010) found that L. japonicus plants carrying a constitutively active form (snf2) of the cytokinin receptor CRE1 display spontaneous development of nodules. This gene action appears to be downstream of calcium/calmodulin-dependent protein kinase (CCAMK) (homolog of M. truncatula DMI3) but requires NIN. In M. truncatula, the engineered autoactive form of CCAMK likewise requires NIN for spontaneous nodule formation (Marsh et al. 2007). It is inferred from these and other studies that cytokinin-induced nodulation acts downstream of CCAMK and upstream of NSP1, NSP2, and NIN (Murray et al. 2007; Tirichine et al. 2007).

In contrast, we found that ATI-induced pseudonodules did form on the dmi3, nspl, nsp2, and nin1 mutants of M. truncatula; thus, CCAMK and the immediately downstream transcriptional steps are not required. We conclude that the action of NPA or TIBA occurs downstream of the core steps of NF signaling. Further, our results are consistent with a model in which ATI induction of pseudonodules is downstream of the cytokinin-induced step or steps. This result is supported by the recent study showing that MtCRE1 cytokinin receptor is required to regulate Medicago spp. NF-signaling genes (Plet et al. 2011).

The ethylene response pathway is also involved in ATIinduced responses. The sickle mutant carries a defect in EIN2, required for response to ethylene (Penmetsa et al. 2008). A connection between auxin transport inhibitors and ethylene has been noted elsewhere: Arabidopsis thaliana pir2, which is allelic to ein2, is resistant to TIBA- and NPA-induced effects on root growth (Fujita and Syŏno 1996). Here, we observed that skll-1 is unable to form pseudonodules in response to TIBA treatment and is impaired for NPA responses. Thus, ethylene appears to have contradictory effects: whereas NPA-induced pseudonodule formation was slightly inhibited by exogenous ethylene, the very formation of pseudonodules by TIBA (and efficient elicitation by NPA) appears to require the ethylene response pathway.

The ethylene requirement for ATI-induced pseudonodulation may be due to ethylene activity at cellular, tissue, or organ levels. The localization of ACC oxidase to particular zones proximal to xylem (Heidstra et al. 1997) is postulated to have an inhibitory effect on cell division. It is possible that local inhibition in one zone of the root is a factor in the stimulation of nodule-like organogenesis in adjacent cells; the lack of EIN2 may result in a more generalized tissue response that does not produce a focused primordium.

At the cellular level, we note that TIBA affects auxin transport by blocking PIN1 cycling; it also inhibits trafficking of membrane proteins unrelated to auxin transport (Geldner et al. 2001). One possible reason for EIN2 requirement might be that sickle 1-1 has an altered PIN1 cycling pattern, affecting the expected TIBA effect on auxin transport. If this were the case, it would be consistent with a role for PIN1 cycling as a component of the pathway that controls nodule initiation. We note that MtPIN1 and MtPIN2 genes are comparably expressed in mock-inoculated controls of WT and sickle M. truncatula (Prayitno et al. 2006). Thus, cycling rather than absolute level may be the most relevant level of interaction between sickle phenotypes and auxin effects.

The failure of $s k l 1-1$ plants to form ATI-induced pseudonodules poses the further question of how this process might relate 
to cytokinin signaling and to cytokinin-induced pseudonodule formation seen in $M$. sativa. Mutant $s k l$ plants do not display cytokinin-induced root shortening (Oldroyd et al. 2001); might EIN2 likewise be required for cytokinin-induced pseudonodules? Because spot-application of cytokinin does not elicit pseudonodule development in $M$. truncatula, it would be instructive to test whether $s k l$ mutants have altered ability to support spontaneous nodules caused by auto-constitutive CCAMK or by cytokinin response mutant $s n f 2$. Such studies will expand the results presented here, showing that manipulation of auxin transport can phenocopy nodule morphogenesis in an EIN2-dependent manner.

\section{MATERIALS AND METHODS}

Plant material, growth conditions, and chemicals.

Genotypes used in this study were $M$. truncatula Gaertner 'Jemalong' A17, dmi1-1, dmi1-2, dmi1-4, dmil-5 (Ané et al. 2004), dmi2-4, dmi3-1, nspl-1 (Catoira et al. 2000), nfp (Amor et al. 2003), nsp2-2 (Oldroyd and Long 2003), rit1 (Mitra and Long 2004), lyk3-1 (Catoira et al. 2001; Smit et al. 2007), nin1 (Marsh et al. 2007), and ern (Middleton et al. 2007). Supernodulator mutants used were sickle1-1 (Penmetsa and Cook 1997), lss (Schnabel et al. 2010), and sunn (Penmetsa et al. 2003). M. truncatula A17 containing a

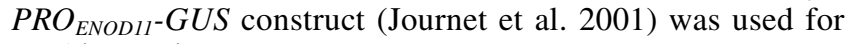
RNAi experiments.

Seed sterilization was performed as described in Mitra and Long (2004). Seed were planted on petri plates (240835; Nunc, Rochester, NY, U.S.A.) containing buffered nodulation medium (BNM) (Ehrhardt et al. 1992), pH 6.5, with $1 \mu$ M AIB and $1.15 \%(\mathrm{wt} / \mathrm{vol})$ agar. Roots treated with ATI were flooded 6 days after planting (dap) using $20 \mathrm{ml}$ of either NPA or TIBA. Excess solution was removed at the bottom of the plate. Stock solutions of NPA and TIBA (Chem Services, Inc., West Chester, PA, U.S.A.) were dissolved in dimethyl sulfoxide and diluted in water to the appropriate final concentrations.

For microarray experiments, 20 plants were grown on BNM plates, $\mathrm{pH} 6.5$, containing $1 \mu \mathrm{M}$ AIB, with either $1.15 \%$ (wt/vol) agar for root segments harvested 1 day after treatment or $2.5 \%$ (wt/vol) agar for roots segments harvested at 7 and 21 days. Roots were exposed to either $200 \mu \mathrm{M}$ NPA or $200 \mu \mathrm{M}$ TIBA. Under these conditions, most of the plants formed pseudonodules by 21 days after ATI treatment. Growth and harvest conditions for microarray experiments using plants inoculated with $e x o A^{-}$bacterial mutant were carried out as described (Starker et al. 2006).

\section{Bacterial strains and growth conditions.}

S. meliloti strain Rm1021 is a streptomycin-resistant derivative of WT S. meliloti strain SU47 (Meade et al. 1982). The exoA $A^{-}$bacterial mutant (RM7031) is described by Leigh and associates (1985). S. meliloti cultures were grown at $30^{\circ} \mathrm{C}$ on Luria-Bertani medium (LB) (Meade et al. 1982) supplemented with the appropriate antibiotics: streptomycin at $500 \mu \mathrm{g} / \mathrm{ml}$ and neomycin at $50 \mu \mathrm{g} / \mathrm{ml}$. For plant transformation experiments, we used Agrobacterium rhizogenes strain ARqual harboring the desired RNAi construct. These strains were grown on LB supplemented with spectinomycin at $50 \mu \mathrm{g} / \mathrm{ml}$ for $24 \mathrm{~h}$ prior to plant transformations.

\section{Plasmid constructions for RNAi.}

Entry clones for RNAi constructs were generated by PCR with Gateway modified primers, using either expressed sequence tags or complementary DNA as template. A complete list of primers, along with the template used for amplification of each of the 17 TC, is shown in Supplementary Table S1. PCR products were cloned into Gateway entry vector $\mathrm{pENTR/D-}$ TOPO (Invitrogen, Carlsbad, CA, U.S.A.). Verified entry clones were exchanged by a Gateway LR reaction into pHellsgate 8dsRed (Pumplin et al. 2010), a modified version of the destination vector pHellsgate8 (Helliwell et al. 2002). The nonrecombinant pHellsgate 8-dsRed vector was used as a negative control. All final clones were verified by sequencing, to check for the presence of inserted sequences and diagnose the orientation of the intron spacer fragment, using the primers $5^{\prime}$-TTCGCAAG ACCCTTCCTCTA-3' and 5'-TTCGTCTTACACATCACTTGT CA-3'.

\section{Plant transformations.}

The constructed RNAi vectors (Supplementary Table S2) were transformed into A. rhizogenes ARqual by the freezethaw method (Höfgen and Willmitzer 1988). Verified transformants were used to generate transgenic hairy roots (BoissonDernier et al. 2001) with the following modifications: transgenic roots were grown for 18 to 20 days on modified Fårhaeus-agar medium supplemented with kanamycin at 20 $\mu \mathrm{g} / \mathrm{ml}$ for selection of transformants; then, plants were transferred to half-strength (1.55 g/liter) Gamborg's B-5 medium (Sigma-Aldrich, St. Louis) for 5 days and transferred to BNM agar plates containing $1 \mu \mathrm{M}$ AIB with filter paper laying on top of the agar (Mega International of Minneapolis, West St. Paul, MN, U.S.A.). Plants were flood inoculated with a solution of $S$. meliloti strain Rm1021 (optical density at $600 \mathrm{~nm}=0.05)$. Two independent experiments were carried out to evaluate nodulation 21 dai for each of the 17 genes targeted for silencing. The 17 genes were evaluated in groups of five or six genes at a time and each experiment included two controls, one where plants were transformed with the nonrecombinant pHellsgate 8 -dsRed vector and a second where plants were transformed with pHellsgate 8-dsRed carrying a SICKLE fragment designated to silence SKL expression. Single roots were harvested and stored at $-80^{\circ} \mathrm{C}$ for RNA isolation and analysis. dsRed expression was confirmed by semiquantitative PCR in all of the samples evaluated by quantitative $(q) P C R$.

\section{GUS promoter fusions.}

In all, five of the $17 \mathrm{TC}$ identified in Figure 5 were found in bacterial artificial chromosomes (BAC) (TC134305, TC115158, TC131096, TC117803, and TC126340). These five TC were further studied for their expression during nodulation. Promoter sequences were PCR amplified from BAC obtained from INRA CNRGV and the Clemson University Genomics Institute. Primers and BAC used are listed in Supplementary Table S3. A 3,000-bp fragment containing the promoter region and a few nucleotides of the coding sequence of the corresponding gene was cloned into pCT8/GW-TOPO (Invitrogen). The entire promoter sequence was confirmed by sequencing. Verified fragments were introduced by a Gateway LR reaction (Invitrogen) into vector pMDC163, which contains a GUS gene. Clones verified by digestion were transformed into A. rhizogenes as described above. As a control for the GUS expression under no symbiotic conditions, we used the nonrecombinant pMDC163 and pCAMBIA DR5::GUS, provided by J. Frugoli. Three experimental replicates were performed and plants were harvested at 1, 4, 7, 14, and 21 dai with WT $S$. meliloti. GUS staining was performed for $8 \mathrm{~h}$ to overnight at $37^{\circ} \mathrm{C}$ with $1 \mathrm{mM}$ 5-bromo-4-chloro-3-indolyl- $\beta$ glucuronic acid, $5 \mathrm{mM}$ EDTA, $0.5 \mathrm{mM}$ potassium ferrocyanide, $0.5 \mathrm{mM}$ potassiumferricyanide, and $0.1 \mathrm{M}$ potassium phosphate, $\mathrm{pH}$ 7.0. Roots harvested after 7 dai were placed under vacuum for $30 \mathrm{~min}$ to allow the GUS staining solution to penetrate the nodule tissue (Oldroyd et al. 2001). 
Affymetrix GeneChip experiments and data analysis.

RNA isolation and preparation for GeneChip experiments is described in the Supplementary Materials and Methods that are published online. Samples harvested at 21 days after treatment were hybridized to the custom $S$. meliloti/M. truncatula SymbiosisChip (Barnett et al. 2004; Mitra et al. 2004). Samples harvested at 1 and 7 days after treatment were hybridized to the GeneChip Medicago Genome Array (Affymetrix, Santa Clara, CA, U.S.A.).

Data analysis as described by Mitra and associates (2004) was performed using dChip analysis software ( $\mathrm{Li}$ and Wong 2001a,b). The criterion for defining a TC with differential expression is if the absolute value of the lower confidence bound of fold change $(|\mathrm{LCB}|)$ is greater than or equal to twofold. Hierarchical clustering using Cluster 3.0 was performed on $\log _{2}$ of fold changes to group genes with similar expression patterns (Eisen et al. 1998). The significance analysis of microarrays (SAM) was used as a second method to identify differentially regulated TC (Tusher et al. 2001). The criterion used in SAM was twofold change in transcriptional expression, with the expectation that no false positives would be chosen. A stand-alone BLAST executable using the program tblastx was run to determine sequence homologies of all identified TC that were differentially regulated. The data discussed in this publication have been deposited in the National Center for Biotechnology Information's Gene Expression Omnibus (GEO) (Edgar et al. 2002) and are accessible through GEO Series accession number GSE28174.

\section{Microscopy to distinguish nodules and pseudonodules.}

Nodulation and pseudonodule formation were evaluated at 21 days by cutting the roots at the hypocotyl and fixed in paraformaldehyde (2.5\% in $0.1 \mathrm{M}$ phosphate buffer, $\mathrm{pH} 7.0$ ) for 15 min under vacuum and 15 min under atmospheric pressure. Fixed roots were washed with distilled water, cleared, and stained with methylene blue $(0.01 \%$ in distilled water) as described by Truchet and associates (1989) and then observed by bright field microscopy.

\section{ACKNOWLEDGMENTS}

Financial support was provided by the Hoover Circle Fund and by funding from the Howard Hughes Medical Institute and from U.S. Department of Energy contract DE-FG03-90ER20010. We thank C. G. Starker for assistance with hairy root transformations, S. Haridas for computer assistance to query the MtGI version 4.0 database to obtain the corresponding TC values in version 8.0, L. Smith for ongoing assistance with plant growth, data analysis, and maintenance, and R. M. Mitra, G. Oldroyd, C. Haney, D. Wang, B. Fisher, M. Barnett, and other members of our lab for discussions and critical reading of the manuscript.

\section{LITERATURE CITED}

Alonso, J. M., Hirayama, T., Roman, G., Nourizadeh, S., and Ecker, J. R. 1999. EIN2, a bifunctional transducer of ethylene and stress responses in Arabidopsis. Science 284:2148-2152.

Amor, B. B., Shaw, S. L., Oldroyd, G. E., Maillet, F., Penmetsa, R. V., Cook, D., Long, S. R., Dénarié, J., and Gough, C. 2003. The NFP locus of Medicago truncatula controls an early step of Nod factor signal transduction upstream of a rapid calcium flux and root hair deformation. Plant J. 34:495-506.

Ané, J. M., Kiss, G. B., Riely, B. K., Penmetsa, R. V., Oldroyd, G. E., Ayax, C., Lévy, J., Debellé, F., Baek, J. M., Kalo, P., Rosenberg, C., Roe, B. A., Long, S. R., Dénarié, J., and Cook, D. R. 2004 Medicago truncatula DMI1 required for bacterial and fungal symbioses in legumes. Science 303:1364-1367.

Barnett, M. J., Toman, C. J., Fisher, R. F., and Long, S. R. 2004. A dualgenome Symbiosis Chip for coordinate study of signal exchange and development in a prokaryote-host interaction. Proc. Natl. Acad. Sci. U.S.A. 101:16636-16641.

Boisson-Dernier, A., Chabaud, M., Garcia, F., Bécard, G., Rosenberg, C., and Barker, D. G. 2001. Agrobacterium rhizogenes-transformed roots of Medicago truncatula for the study of nitrogen-fixing and endomycorrhizal symbiotic associations. Mol. Plant-Microbe Interact. 14:695700.

Caetano-Anollés, G., Lagares, A., and Bauer, W. D. 1990a. Rhizobium meliloti exopolysaccharide mutants elicit feedback regulation of nodule formation in alfalfa. Plant Physiol. 91:368-374.

Caetano-Anollés, G., Priyavadan, A. J., and Gresshoff, P. M. 1990b. Spontaneous nodules induce feedback suppression of nodulation in alfalfa. Planta 183:77-82.

Catoira, R., Galera, C., de Billy, F., Penmetsa, R. V., Journet, E. P., Maillet, F., Rosenberg, C., Cook, D., Gough, C., and Dénarié, J. 2000. Four genes of Medicago truncatula controlling components of a nod factor transduction pathway. Plant Cell 12:1647-1666.

Catoira, R., Timmers, A. C., Maillet, F., Galera, C., Penmetsa, R. V., Cook, D., Dénarié, J., and Gough, C. 2001. The HCL gene of Medicago truncatula controls Rhizobium-induced root hair curling. Development 128:1507-1518.

Cook, D., Dreyer, D., Bonnet, D., Howell, M., Nony, E., and VandenBosch, K. 1995. Transient induction of a peroxidase gene in Medicago truncatula precedes infection by Rhizobium meliloti. Plant Cell 7:43-55.

Cooper, J. B., and Long, S. R. 1994. Morphogenetic rescue of Rhizobium meliloti nodulation mutants by trans-Zeatin secretion. Plant Cell 6:215225.

Edgar, R., Domrachev, M., and Lash, A. E. 2002. Gene Expression Omnibus: NCBI gene expression and hybridization array data repository. Nucleic Acids Res. 30:207-210.

Ehrhardt, D. W., Atkinson, E. M., and Long, S. R. 1992. Depolarization of alfalfa root hair membrane potential by Rhizobium meliloti Nod factors. Science 256:998-1000.

Eisen, M. B., Spellman, P. T., Brown, P. O., and Botstein, D. 1998. Cluster analysis and display of genome-wide expression patterns. Proc. Natl. Acad. Sci. U.S.A. 95:14863-14868.

Ferguson, B. J., Ross, J. J., and Reid, J. B. 2005. Nodulation phenotypes of gibberellin and brassinosteroid mutants of pea. Plant Physiol. 138:2396-2405.

Fujita, H., and Syŏno, K. 1996. Genetic analysis of the effects of polar auxin transport inhibitors on root growth in Arabidopsis thaliana. Plant Cell Physiol. 37:1094-1101.

Gamas, P., Niebel Fde, C., Lescure, N., and Cullimore, J. 1996. Use of a subtractive hybridization approach to identify new Medicago truncatula genes induced during root nodule development. Mol. Plant-Microbe Interact. 9:233-242.

Gamas, P., de Billy, F., and Truchet, G. 1998. Symbiosis-specific expression of two Medicago truncatula nodulin genes, MtN1 and MtN13, encoding products homologous to plant defense proteins. Mol. PlantMicrobe Interact. 11:393-403.

Geldner, N., Friml, J., Stierhof, Y. D., Jürgens, G., and Palme, K. 2001. Auxin transport inhibitors block PIN1 cycling and vesicle trafficking. Nature 413:425-428.

Heidstra, R., Yang, W. C., Yalcin, Y., Peck, S., Emons, A. M., van Kammen, A., and Bisseling, T. 1997. Ethylene provides positional information on cortical cell division but is not involved in Nod factor-induced root hair tip growth in Rhizobium-legume interaction. Development 124:1781-1787.

Helliwell, C. A., Wesley, S. V., Wielopolska, A. J., and Waterhouse, P. M. 2002. High-throughput vectors for efficient gene silencing in plants. Funct. Plant Biol. 29:1217-1225.

Hirsch, A. M., Bhuvaneswari, T. V., Torrey, J. G., and Bisseling, T. 1989. Early nodulin genes are induced in alfalfa root outgrowths elicited by auxin transport inhibitors. Proc. Natl. Acad.Sci. U.S.A. 86:12441248.

Höfgen, R., and Willmitzer, L. 1988. Storage of competent cells for Agrobacterium transformation. Nucleic Acids Res. 16:9877.

Jones, K. M., Sharopova, N., Lohar, D. P., Zhang, J. Q., VandenBosch, K. A., and Walker, G. C. 2008 Differential response of the plant Medicago truncatula to its symbiont Sinorhizobium meliloti or an exopolysaccharide-deficient mutant. Proc. Natl. Acad. Sci. U.S.A. 105:704-709.

Journet, E. P., El-Gachtouli, N., Vernoud, V., de Billy, F., Pichon, M., Dedieu, A., Arnould, C., Morandi, D., Barker, D. G., and GianinazziPearson, V. 2001. Medicago truncatula ENOD11: A novel RPRPencoding early nodulin gene expressed during mycorrhization in arbuscule-containing cells. Mol. Plant-Microbe Interact. 14:737-748.

Leigh, J. A., Signer, E. R., and Walker, G. C. 1985. Exopolysaccharide-deficient mutants of Rhizobium meliloti that form ineffective nodules. Proc. Natl. Acad. Sci. U.S.A. 82:6231-6235.

Li, C., and Wong, W. H. 2001a. Model-based analysis of oligonucleotide arrays: Expression index computation and outlier detection. Proc. Natl. Acad. Sci. U.S.A. 98:31-36.

Li, C., and Wong, W. H. 2001b. Model-based analysis of oligonucleotide 
arrays: Model validation, design issues and standard error application. Genome Biol. 2:32.31-32.11.

Long, S. R., and Cooper, J. B. 1988. Overview of symbiosis. Pages $163-$ 178 in: Molecular Genetics of Plant-Microbe Interactions. R. Palacios and D. P. S. Verma, eds. American Phytopathological Society, St. Paul, MN, U.S.A.

Madsen, L. H., Tirichine, L., Jurkiewicz, A., Sullivan, J. T., Heckmann, A. B., Bek, A. S., Ronson, C. W., James, E. K., and Stougaard, J. 2010. The molecular network governing nodule organogenesis and infection in the model legume Lotus japonicus. Nature Commun. 1:10.

Marsh, J. F., Rakocevic, A., Mitra, R. M., Brocard, L., Sun, J., Eschstruth, A., Long, S. R., Schultze, M., Ratet, P., and Oldroyd, G. E. 2007. Medicago truncatula NIN is essential for Rhizobium-independent nodule organogenesis induced by autoactive CCaMK. Plant Physiol. 144:324335 .

Meade, H. M., Long, S. R., Ruvkun, G. B., Brown, S. E., and Ausubel, F. M. 1982. Physical and genetic characterization of symbiotic and auxotrophic mutants of Rhizobium meliloti induced by transposon Tn5 mutagenesis. J. Bacteriol. 149:114-122.

Middleton, P. H., Jakab, J., Penmetsa, R. V., Starker, C. G., Doll, J., Kalo, P., Prabhu, R., Marsh, J. F., Mitra, R. M., Kereszt, A., Dudas, B., VandenBosch, K., Long, S. R., Cook, D. R., Kiss, G. B., and Oldroyd, G. E. 2007. An ERF transcription factor in Medicago truncatula that is essential for Nod factor signal transduction. Plant Cell 19:1221-1234.

Mitra, R. M., and Long, S. R. 2004. Plant and bacterial symbiotic mutants define three transcriptionally distinct stages in the development of the Medicago truncatula/Sinorhizobium meliloti symbiosis. Plant Physiol. 134:1-10.

Mitra, R. M., Shaw, S. L., and Long, S. R. 2004. Six nonnodulating plant mutants defective for Nod factor-induced transcriptional changes associated with the legume-rhizobia symbiosis. Proc. Natl. Acad. Sci. U.S.A. 101:10217-10222.

Murray, J. D., Karas, B. J., Sato, S., Tabata, S., Amyot, L., and Szczyglowski, K. 2007. A cytokinin perception mutant colonized by Rhizobium in the absence of nodule organogenesis. Science 315:101104

Oldroyd, G. E., and Long, S. R. 2003. Identification and characterization of nodulation-signaling pathway 2, a gene of Medicago truncatula involved in Nod Factor signaling. Plant Physiol. 131:1027-1032.

Oldroyd, G. E., Engstrom, E. M., and Long, S. R. 2001. Ethylene inhibits the Nod factor signal transduction pathway of Medicago truncatula. Plant Cell 13:1835-1849.

Penmetsa, R. V., and Cook, D. R. 1997. A legume ethylene-insensitive mutant hyperinfected by its rhizobial symbiont. Science 275:527-530.

Penmetsa, R. V., Frugoli, J. A., Smith, L. S., Long, S. R., and Cook, D. R. 2003. Dual genetic pathways controlling nodule number in Medicago truncatula. Plant Physiol. 131:998-1008.

Penmetsa, R. V., Uribe, P., Anderson, J., Lichtenzveig, J., Gish, J.-C., Nam, Y. W., Engstrom, E., Xu, K., Sckisel, G., Pereira, M., Baek, J. M., Lopez-Meyer, M., Long, S. R., Harrison, M. J., Singh, K. B., Kiss, G. B., and Cook, D. R. 2008. The Medicago truncatula ortholog of Arabidopsis EIN2, sickle, is a negative regulator of symbiotic and pathogenic microbial associations. Plant J. 55:1-16.

Plet, J., Wasson, A., Ariel, F., Le Signor, C., Baker, D., Mathesius, U., Crespi, M., and Frugier, F. 2011. MtCRE1-dependent cytokinin signaling integrates bacterial and plant cues to coordinate symbiotic nodule organogenesis in Medicago truncatula. Plant J. 65:622-633.

Prayitno, J., Rolfe, B. G., and Mathesius, U. 2006. The ethylene-insensitive sickle mutant of Medicago truncatula shows altered auxin transport regulation during nodulation. Plant Physiol. 142:168-180.

Pumplin, N., Mondo, S. J., Topp, S., Starker, C. G., Gantt, J. S., and Harrison, M. J. 2010 Medicago truncatula Vapyrin is a novel protein required for arbuscular mycorrhizal symbiosis. Plant J. 61:482-494.

Schnabel, E., Mukherjee, A., Smith, L., Kassaw, T., Long, S., and Frugoli,
J. 2010. The lss supernodulation mutant of Medicago truncatula reduces expression of the SUNN gene. Plant Physiol. 154:1390-1402.

Smit, P., Limpens, E., Geurts, R., Fedorova, E., Dolgikh, E., Gough, C., and Bisseling, T. 2007. Medicago LYK3, an entry receptor in rhizobial nodulation factor signaling. Plant Physiol. 145:183-191.

Stacey, G., McAlvin, C. B., Kim, S. Y., Olivares, J., and Soto, M. J. 2006 Effects of endogenous salicylic acid on nodulation in the model legumes Lotus japonicus and Medicago truncatula. Plant Physiol. 141:1473-1481.

Starker, C. G., Parra-Colmenares, A. L., Smith, L., Mitra, R. M., and Long, S. R. 2006. Nitrogen fixation mutants of Medicago truncatula fail to support plant and bacterial symbiotic gene expression. Plant Physiol. 140:671-680.

Sun, J., Cardoza, V., Mitchell, D. M., Bright, L., Oldroyd, G., and Harris, J. M. 2006. Crosstalk between jasmonic acid, ethylene and Nod factor signaling allows integration of diverse inputs for regulation of nodulation. Plant J. 46:961-970.

Suzuki, A., Akune, M., Kogiso, M., Imagama, Y., Osuki, K., Uchiumi, T., Higashi, S., Han, S. Y., Yoshida, S., Asami, T., and Abe, M. 2004. Control of nodule number by the phytohormone abscisic Acid in the roots of two leguminous species. Plant Cell Physiol. 45:914-922.

Tirichine, L., Sandal, N., Madsen, L. H., Radutoiu, S., Albrektsen, A. S., Sato, S., Asamizu, E., Tabata, S., and Stougaard, J. 2007. A gain-offunction mutation in a cytokinin receptor triggers spontaneous root nodule organogenesis. Science 315:104-107.

Truchet, G., Camut, S., de Billy, F., Odorico, R., and Vasse, J. 1989. The Rhizobium-legume symbiosis two methods to discriminate between nodules and other root-derived structures. Protoplasma 149:82-88.

Tusher, V. G., Tibshirani, R., and Chu, G. 2001. Significance analysis of microarrays applied to the ionizing radiation response. Proc. Natl. Acad. Sci. U.S.A. 98:5116-5121.

Van De Wiel, C., Norris, J. H., Bochenek, B., Dickstein, R., Bisseling, T., and Hirsch, A. M. 1990 Nodulin gene expression and ENOD2 localization in effective, nitrogen-fixing and ineffective, bacteria-free nodules of alfalfa. Plant Cell 2:1009-1017.

Van Eldik, G. J., Wingens, M., Ruiter, R. K., Van Herpen, M. M., Schrauwen, J. A., and Wullems, G. J. 1996. Molecular analysis of a pistilspecific gene expressed in the stigma and cortex of Solanum tuberosum. Plant Mol. Biol. 30:171-176.

van Noorden, G. E., Ross, J. J., Reid, J. B., Rolfe, B. G., and Mathesius, U. 2006. Defective long-distance auxin transport regulation in the Medicago truncatula super numeric nodules mutant. Plant Physiol. 140:1494-1506.

Vernié, T., Moreau, S., de Billy, F., Plet, J., Combier, J. P., Rogers, C., Oldroyd, G., Frugier, F., Niebel, A., and Gamas, P. 2008. EFD Is an ERF transcription factor involved in the control of nodule number and differentiation in Medicago truncatula. Plant Cell 20:2696-2713.

Wasson, A. P., Pellerone, F. I., and Mathesius, U. 2006. Silencing the flavonoid pathway in Medicago truncatula inhibits root nodule formation and prevents auxin transport regulation by rhizobia. Plant Cell 18:16171629

Wen, J., Lease, K. A., and Walker, J. C. 2004 DVL, a novel class of small polypeptides: Overexpression alters Arabidopsis development. Plant J. 37:668-677.

Woo, H. H., Orbach, M. J., Hirsch, A. M., and Hawes, M. C. 1999 Meristem-localized inducible expression of a UDP-glycosyltransferase gene is essential for growth and development in pea and alfalfa. Plant Cell $11: 2303-2315$.

\section{AUTHOR-RECOMMENDED INTERNET RESOURCE}

NCBI Gene Expression Onmibus series GSE28174: www.ncbi.nlm.nih.gov/geo/query/acc.cgi?acc=GSE28174 